University of South Florida

DIGITAL COMMONS

Digital Commons @ University of

@ UNIVERSITY OF SOUTH FLORIDA

South Florida

$3-2013$

\title{
Inter-annual to Decadal Sea-level Variability in the Coastal Zones of the Norwegian and Siberian Seas: The Role of Atmospheric Forcing
}

\author{
F. M. Calafat \\ University of South Florida \\ D. P. Chambers \\ University of South Florida, donc@usf.edu \\ M. N. Tsimplis \\ National Oceanography Centre, Southampton, UK
}

Follow this and additional works at: https://digitalcommons.usf.edu/msc_facpub

Part of the Life Sciences Commons

\section{Scholar Commons Citation}

Calafat, F. M.; Chambers, D. P.; and Tsimplis, M. N., "Inter-annual to Decadal Sea-level Variability in the Coastal Zones of the Norwegian and Siberian Seas: The Role of Atmospheric Forcing" (2013). Marine Science Faculty Publications. 1416.

https://digitalcommons.usf.edu/msc_facpub/1416

This Article is brought to you for free and open access by the College of Marine Science at Digital Commons @ University of South Florida. It has been accepted for inclusion in Marine Science Faculty Publications by an authorized administrator of Digital Commons @ University of South Florida. For more information, please contact digitalcommons@usf.edu. 


\title{
Inter-annual to decadal sea-level variability in the coastal zones of the Norwegian and Siberian Seas: The role of atmospheric forcing
}

\author{
F. M. Calafat, ${ }^{1,2}$ D. P. Chambers, ${ }^{1}$ and M. N. Tsimplis ${ }^{2}$ \\ Received 15 October 2012; revised 23 January 2013; accepted 29 January 2013; published 18 March 2013.
}

[1] Inter-annual to decadal sea-level variations from tide gauge records in the coastal zones of the Norwegian and Siberian Seas are examined for the period 1950-2010 using a combination of hydrographic observations, wind data, and theory. We identify two large areas of highly coherent sea-level variability: one that includes the Norwegian, Barents, and Kara Seas, and another one that includes the Laptev, East Siberian, and Chukchi Seas. We provide evidence of a new contribution to the sea-level variability along the Norwegian coast associated with the poleward propagation of sea-level fluctuations along the eastern boundary of the North Atlantic. When this propagating signal is combined with the local wind, we are able to explain over $70 \%$ of the variance along the Norwegian coast. The steric component explains $\sim 61 \%$ of the sea-level (corrected for the inverse barometer) variability along the Norwegian coast. The high coherency between the sea level along the Norwegian coast and that in the Barents and Kara Seas suggests that part of the Norwegian signal propagates further north into these regions. We introduce an atmospheric vorticity index that explains much of the sea-level variability in the Laptev, East Siberian, and Chukchi Seas with correlations ranging from 0.73 to 0.81 . In the East Siberian Sea, we identify a sea-level increase of $22 \mathrm{~cm}$ between 2000 and 2003, which is partly explained by the vorticity index, and a decline of $\sim 15 \mathrm{~cm}$ after 2003, which we relate to the strengthening of the Beaufort Gyre.

Citation: Calafat, F. M., D. P. Chambers, and M. N. Tsimplis (2013), Inter-annual to decadal sea-level variability in the coastal zones of the Norwegian and Siberian Seas: The role of atmospheric forcing, J. Geophys. Res. Oceans, 118, 1287-1301, doi:10.1002/jgrc.20106.

\section{Introduction}

[2] Global mean sea level (GMSL) has been rising at an average rate of $1.7 \pm 0.2 \mathrm{~mm} /$ year during the past century [Church and White, 2011], and recent projections suggest a GMSL rise of $0.19 \mathrm{~m}$ [Meehl et al., 2007] to $1.9 \mathrm{~m}$ [Vermeer and Rahmstorf, 2009] by the end of the 21st century. However, the increase in sea level has varied greatly by region, with some regions experiencing a sealevel rise significantly greater than the global average [e.g., Cazenave and Llovel, 2010]. Furthermore, regional sea level exhibits significant inter-annual and decadal variability with considerably higher amplitudes than those in GMSL. Improving our understanding of the mechanisms that cause the higher regional sea-level variations is, hence, required to reduce the uncertainties in regional sea-level projections. As such, there have been, in recent years, a series of studies that have focused on understanding and quantifying the

\footnotetext{
${ }^{1}$ College of Marine Science, University of South Florida, St. Petersburg, Florida, USA.

${ }^{2}$ National Oceanography Centre, Southampton, UK.

Corresponding author: F. M. Calafat, College of Marine Science, University of South Florida, 140 7th Ave. S, St. Petersburg, FL 33713, USA. (Francisco.Calafat@noc.ac.uk)

(C)2013. American Geophysical Union. All Rights Reserved. 2169-9275/13-0/10.1002/jgrc.20106
}

magnitude of regional sea-level variability. Examples of such studies can be found for the North Atlantic [Miller and Douglas, 2007; Marcos and Tsimplis, 2007; Woodworth et al., 2010; Sturges and Douglas, 2011; Llovel et al., 2011; Calafat et al., 2012a], the western Pacific [Merrifield, 2011; Marcos et al., 2012], the eastern Pacific [Bromirski et al., 2011], and the Mediterranean Sea [Tsimplis et al., 2008; Meyssignac et al., 2011; Calafat et al., 2012b]. One area where long-term sea-level variability has not been extensively studied is the Arctic Ocean, mainly due to lack of observations until quite recently. Our aim here is to explore the sea-level variability from tide gauge records in the coastal zones of the Norwegian and Siberian Seas (see Figure 1 for map of the regions) at inter-annual to decadal time scales and to propose plausible driving mechanisms for the sea-level variations.

[3] The study of the sea-level variability in the Arctic is important not only to coastal communities living in the area, which are already suffering the effects of the sea-level rise [Forman and Johnson, 1998], but also to people living elsewhere in the world, as changes in the Arctic Ocean can affect the global climate through their impact on the global ocean's overturning circulation [Bindoff et al., 2007]. Moreover, there is also recent evidence of significant interactions between the Arctic and the other oceans by means of water mass exchanges [Morison et al., 2007], which in turn can 


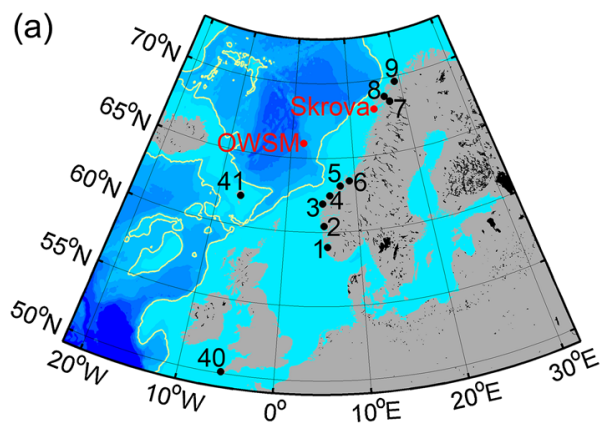

(b)

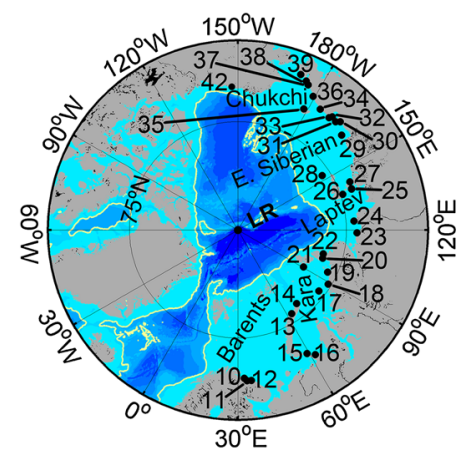

Figure 1. Maps showing the location of tide gauge stations (a) along the Norwegian coast and (b) in the Arctic Seas. Numbers correspond to the tide gauge stations shown in Table 1. Red dots show the location of the hydrographic stations Skrova and OWSM. The location of the Barents and Siberian Seas as well as the bathymetry are also shown. Depth contour interval is $500 \mathrm{~m}$, with the yellow line indicating the $1000 \mathrm{~m}$ bathymetric contour. LR, Lomonosov Ridge.

affect sea level in other regions of the world. In recent years, several studies have focused on studying Arctic sea-level variability [e.g., Proshutinsky et al., 2001, 2004, 2007, 2009, 2011; Henry et al., 2012; Volkov and Pujol, 2012], most of which are based on a set of tide gauge data collected by the Arctic and Antarctic Research Institute (in St. Petersburg, Russia) that was released in 2003, either alone or in combination with ocean models. Proshutinsky et al. [2001, 2004, 2007] explored the long-term sea-level variability in the Arctic on the basis of tide gauge observations and the outputs of 2-D and 3-D numerical models. They found that in the Barents and Kara Seas, the inverse barometer (IB) effect dominates over the effect of the wind at inter-annual time scales, while in the Laptev, East Siberian, and Chukchi Seas, where the shelf is relatively shallow, the wind is a major contributor to sea-level variability. They also found significant correlation between the low pass-filtered (5 year running mean) sea level from tide gauge records in the Siberian Seas and the Arctic Oscillation (AO) index for the period 1962-1998, confirming the relationship between sea-level and large-scale atmospheric forcing. Interestingly, they found that the good agreement with the AO index vanishes after around 1999. A similar result was also found by Henry et al. [2012]. The loss of correlation with the AO index is mainly due to a relatively rapid sea-level rise after 1999 that is not reflected in the AO index. The forcing mechanism responsible for this sealevel rise was not identified in the previous studies.
[4] Another region that has received particular attention in recent years is the Nordic Seas [Richter et al., 2012a, 2012b; Henry et al., 2012; Volkov and Pujol, 2012]. This region is highly vulnerable to a sea-level rise due to its partially low-lying coasts. It also plays an important role as a supplier of dense water for the Atlantic meridional overturning circulation [Rahmstorf, 2006]. In a recent paper, Richter et al. [2012a] have explored the different contributions to sealevel variability along the Norwegian coast at seasonal and longer time scales. In particular, they have combined estimates of the IB effect, the steric component, and the effect of land uplift in order to explain the observed sea-level variability and quantify the relative contribution of each component. They have found that the IB effect slightly dominates over the steric component and explains between $30 \%$ and $50 \%$ of the inter-annual sea-level variability. When the IB effect is combined with the steric component, they are able to explain between $38 \%$ and $75 \%$ of the total variance, depending on the location of the tide gauge. They have also found that the contribution of the IB effect diminishes as the time scale increases, whereas that of the thermosteric component increases. Contrary to those results, Henry et al. [2012] found no significant correlation between the inter-annual (IB-corrected and detrended) sea-level variability and the steric component of sea level along the Norwegian coast, which led them to the conclusion that the mass component may dominate over the steric at such time scales. Hence, the relative contribution of the two components of sea level (i.e., the steric and mass components) is not clear. Also, while the effect of northeastward winds blowing over the region is known to be responsible for part of the IB-corrected sea-level variability along the Norwegian coast [Richter et al., 2012b], a considerable fraction of the variability is not explained by this effect, which suggests the existence of additional driving mechanisms.

[5] Despite the significant improvement in our understanding of the long-term sea-level variability both in the Arctic Ocean and along the Norwegian coast, there are certain aspects of the sea-level variability that are still not well understood. One of them is the sea-level variability in the Siberian Seas after 1999. The relative contribution of the steric and mass components to the IB-corrected interannual sea-level variability along the Norwegian coast and the precise driving mechanisms is another one. In this paper, we use a combination of hydrographic observations, wind stress data, and theory to explore the inter-annual to decadal sea-level variability from tide gauge records along the coastal zones of the Norwegian and Siberian Seas since 1950. We propose plausible driving mechanisms that help us explain some of the aspects of the variability whose causes are unclear, such as those discussed earlier. In particular, we provide evidence of a contribution to the sea-level variability along the Norwegian coast that has its origin in a large-scale sealevel signal propagating poleward along the eastern boundary of the North Atlantic. We will show that much of the sea-level variability in the Laptev, East Siberian, and Chukchi Seas can be explained by shifts between cyclonic or anti-cyclonic atmospheric circulation over the Laptev and the East Siberian Seas. A vorticity index is used to characterize these shifts in atmospheric circulation. We will also show that the previously reported but unexplained sea-level increase after 1999 was particularly large $(\sim 22 \mathrm{~cm})$ in the East Siberian Sea and was 
followed by a sea-level decline of similar magnitude from 2004 to 2008. The vorticity index explains much of this increase in the East Siberian Sea, but it fails to reproduce the subsequent decline. We will relate such decline in sea level to the strengthening of the Beaufort Gyre observed in recent years [Proshutinsky et al., 2009; Giles et al., 2012].

\section{Data}

[6] Monthly averaged time series of sea level are obtained from the Revised Local Reference data archive of the Permanent Service for Mean Sea Level [Woodworth and Player, 2003]. For further details on the quality and accuracy of the Russian tide gauges used in this analysis, the reader is referred to Proshutinsky et al. [2004]. Tide gauge stations are selected according to the following criteria. First, we select all tide gauge records that have at least 30 years of data (in the Norwegian Sea, we use a criterion of 50 years of data as many tide gauge records in that region span more than 50 years) within the period 1950-2010 and less than $15 \%$ of missing data. Tide gauge stations located near the mouth of rivers are rejected. Second, the selected tide gauge records are grouped into six geographical regions, namely, the Norwegian Coast, the Barents Sea, the Kara Sea, the Laptev Sea, the East Siberian Sea, and the Chukchi Sea (Figure 1). Since our focus is on the inter-annual to decadal time scales, the seasonal cycle, together with a linear trend, is removed from all tide gauge records. Finally, we perform a cross-correlation analysis for each pair of tide gauge records and for each region (i.e., six cross-correlation analyses) in order to identify those that exhibit a similar variability. Tide gauge records that do not show statistically significant correlation with all other records within its region are rejected. This is to ensure that all selected tide gauge records are representative of the large-scale sea-level variability of the region where they are located. Nine tide gauge records were rejected due to their low correlation with regional sea level.

[7] As a result of this analysis, the number of selected tide gauge records is as follows: nine along the Norwegian coast, five in the Barents Sea, eight in the Kara Sea, four in the Laptev Sea, eight in the East Siberian Sea, and five in the Chukchi Sea. The name, location, period covered, and percentage of missing data for all selected stations are shown in Table 1 and also in Figure 1. Finally, an average time

Table 1. Station Number, Station Name, Region Where the Station Is Located, Its Position (in Latitude and Longitude), Period Covered, and Percentage of Missing Data

\begin{tabular}{|c|c|c|c|c|c|c|}
\hline \# & Name & Region & Latitude & Longitude & Period & Gaps (\%) \\
\hline 1 & Stavanger & Norwegian Sea & $58.97^{\circ} \mathrm{N}$ & $5.73^{\circ} \mathrm{E}$ & $1948-2010$ & 3.0 \\
\hline 2 & Bergen & Norwegian Sea & $60.40^{\circ} \mathrm{N}$ & $5.30^{\circ} \mathrm{E}$ & 1948-2010 & 2.6 \\
\hline 3 & Maloy & Norwegian Sea & $61.93^{\circ} \mathrm{N}$ & $5.12^{\circ} \mathrm{E}$ & 1948-2010 & 6.3 \\
\hline 4 & Alesund & Norwegian Sea & $62.47^{\circ} \mathrm{N}$ & $6.15^{\circ} \mathrm{E}$ & $1951-2010$ & 1.9 \\
\hline 5 & Kristiansund & Norwegian Sea & $63.12^{\circ} \mathrm{N}$ & $7.73^{\circ} \mathrm{E}$ & 1953-2010 & 1.3 \\
\hline 6 & Heimsjo & Norwegian Sea & $63.43^{\circ} \mathrm{N}$ & $9.12^{\circ} \mathrm{E}$ & $1948-2010$ & 2.0 \\
\hline 7 & Narvik & Norwegian Sea & $68.43^{\circ} \mathrm{N}$ & $17.42^{\circ} \mathrm{E}$ & $1948-2010$ & 1.5 \\
\hline 8 & Harstad & Norwegian Sea & $68.80^{\circ} \mathrm{N}$ & $16.55^{\circ} \mathrm{E}$ & 1953-2010 & 5.2 \\
\hline 9 & Tromso & Norwegian Sea & $69.65^{\circ} \mathrm{N}$ & $18.97^{\circ} \mathrm{E}$ & $1953-2010$ & 1.4 \\
\hline 10 & Mys Pikshueva & Barents Sea & $69.55^{\circ} \mathrm{N}$ & $32.43^{\circ} \mathrm{E}$ & 1956-1990 & 14.8 \\
\hline 11 & Polyarniy & Barents Sea & $69.20^{\circ} \mathrm{N}$ & $33.48^{\circ} \mathrm{N}$ & 1950-1990 & 0.0 \\
\hline 12 & Teriberka & Barents Sea & $69.20^{\circ} \mathrm{N}$ & $35.12^{\circ} \mathrm{E}$ & 1950-1990 & 4.3 \\
\hline 13 & Russkaya Gavan & Barents Sea & $76.20^{\circ} \mathrm{N}$ & $62.58^{\circ} \mathrm{E}$ & 1953-1990 & 0.7 \\
\hline 14 & Zhelania II & Barents Sea & $76.95^{\circ} \mathrm{N}$ & $68.55^{\circ} \mathrm{N}$ & 1951-1995 & 2.2 \\
\hline 15 & Bolvanskii Nos & Kara Sea & $70.45^{\circ} \mathrm{N}$ & $59.08^{\circ} \mathrm{E}$ & 1951-1992 & 0.0 \\
\hline 16 & Amderma & Kara Sea & $69.75^{\circ} \mathrm{N}$ & $61.70^{\circ} \mathrm{E}$ & 1950-2009 & 1.8 \\
\hline 17 & Izvestia Tsik & Kara Sea & $75.95^{\circ} \mathrm{N}$ & $82.95^{\circ} \mathrm{E}$ & 1954-2009 & 0.0 \\
\hline 18 & Sterlegova & Kara Sea & $75.42^{\circ} \mathrm{N}$ & $88.90^{\circ} \mathrm{E}$ & 1950-1994 & 0.0 \\
\hline 19 & Pravdy & Kara Sea & $76.27^{\circ} \mathrm{N}$ & $94.77^{\circ} \mathrm{E}$ & 1950-1993 & 0.2 \\
\hline 20 & Geiberga & Kara Sea & $77.60^{\circ} \mathrm{N}$ & $101.52^{\circ} \mathrm{E}$ & 1951-1994 & 1.1 \\
\hline 21 & Golomianyi & Kara Sea & $79.55^{\circ} \mathrm{N}$ & $90.62^{\circ} \mathrm{E}$ & 1954-2008 & 1.7 \\
\hline 22 & Fedorova & Kara Sea & $77.72^{\circ} \mathrm{N}$ & $104.30^{\circ} \mathrm{N}$ & 1950-1989 & 0.0 \\
\hline 23 & Terpiai-Tumsa & Laptev Sea & $73.55^{\circ} \mathrm{N}$ & $118.67^{\circ} \mathrm{N}$ & 1956-1997 & 1.8 \\
\hline 24 & Dunai & Laptev Sea & $73.93^{\circ} \mathrm{N}$ & $124.50^{\circ} \mathrm{E}$ & 1951-2009 & 1.0 \\
\hline 25 & Kigiliah & Laptev Sea & $73.33^{\circ} \mathrm{N}$ & $139.87^{\circ} \mathrm{E}$ & 1951-2009 & 0.4 \\
\hline 26 & Sannikova & Laptev Sea & $74.67^{\circ} \mathrm{N}$ & $138.90^{\circ} \mathrm{E}$ & 1951-2008 & 1.7 \\
\hline 27 & Shalaurova & East Siberian Sea & $73.18^{\circ} \mathrm{N}$ & $143.23^{\circ} \mathrm{E}$ & $1950-2000$ & 1.5 \\
\hline 28 & Zhohova & East Siberian Sea & $76.15^{\circ} \mathrm{N}$ & $152.83^{\circ} \mathrm{E}$ & 1959-1992 & 2.9 \\
\hline 29 & Chetyrehstolbovoi & East Siberian Sea & $70.63^{\circ} \mathrm{N}$ & $162.48^{\circ} \mathrm{E}$ & 1951-1993 & 0.0 \\
\hline 30 & Rau-Chua & East Siberian Sea & $69.93^{\circ} \mathrm{N}$ & $166.58^{\circ} \mathrm{N}$ & 1950-1989 & 0.0 \\
\hline 31 & Aion & East Siberian Sea & $69.93^{\circ} \mathrm{N}$ & $167.98^{\circ} \mathrm{E}$ & 1954-2006 & 9.9 \\
\hline 32 & Pevek & East Siberian Sea & $69.70^{\circ} \mathrm{N}$ & $170.25^{\circ} \mathrm{E}$ & 1950-2009 & 6.8 \\
\hline 33 & Valkarkai & East Siberian Sea & $70.08^{\circ} \mathrm{N}$ & $170.93^{\circ} \mathrm{E}$ & 1956-1992 & 1.6 \\
\hline 34 & Billinga & East Siberian Sea & $69.88^{\circ} \mathrm{N}$ & $175.77^{\circ} \mathrm{E}$ & 1953-1994 & 0.0 \\
\hline 35 & Vrangelia & Chukchi Sea & $70.98^{\circ} \mathrm{N}$ & $178.48^{\circ} \mathrm{W}$ & 1950-2000 & 1.3 \\
\hline 36 & Mys Shmidta & Chukchi Sea & $68.90^{\circ} \mathrm{N}$ & $179.37^{\circ} \mathrm{W}$ & 1950-1993 & 0.0 \\
\hline 37 & Vankarem & Chukchi Sea & $67.83^{\circ} \mathrm{N}$ & $175.83^{\circ} \mathrm{W}$ & 1950-2000 & 9.5 \\
\hline 38 & Koluchin & Chukchi Sea & $67.48^{\circ} \mathrm{N}$ & $174.65^{\circ} \mathrm{W}$ & 1950-1991 & 0.0 \\
\hline 39 & Netten & Chukchi Sea & $66.97^{\circ} \mathrm{N}$ & $171.93^{\circ} \mathrm{W}$ & 1950-1994 & 1.3 \\
\hline 40 & Newlyn & North Atlantic & $50.10^{\circ} \mathrm{N}$ & $5.54^{\circ} \mathrm{W}$ & 1948-2010 & 1.7 \\
\hline 41 & Torshavn & Faroe Islands & $62.02^{\circ} \mathrm{N}$ & $6.77^{\circ} \mathrm{W}$ & $1958-2006$ & 16.7 \\
\hline 42 & Prudhoe Bay & Alaska & $70.40^{\circ} \mathrm{N}$ & $148.53^{\circ} \mathrm{W}$ & $1995-2010$ & 1.6 \\
\hline
\end{tabular}


series of sea level is computed for each of the six regions by averaging the sea level for all tide gauges located in the same region. None of the resulting average time series have any gaps, except for that of the East Siberian Sea. Since all gaps in the East Siberian time series are smaller than 3 months, we fill them using spline interpolation. Finally, a 2 year (25 months) central running mean is applied to each time series. Note that tide gauge records within any given region span different time periods, and thus, the number of tide gauge records used to compute the average time series of sea level varies with time. The uncertainty associated to each average time series is computed as the standard deviation of the mean for each month.

[8] Sea-level pressure (SLP) and wind stress data are obtained from the National Centers for Environmental Prediction (NCEP) reanalysis [Kalnay et al., 1996]. They are monthly fields on a $2.5^{\circ} \times 2.5^{\circ}$ global grid covering the period from 1948 to present. On the basis of comparisons of the IB effect estimated from different data sets, Ponte [2006] found that SLP from NCEP provided a good estimate of the IB effect in the Arctic at inter-annual time scales.

[9] Gridded sea-level anomaly (SLA) fields from satellite altimetry were collected from the delayed time AVISO products that are available at http://www.aviso.oceanobs.com. Here we use the reference ("Ref") series, which are based on two satellites (Jason-2/Envisat or Jason-1/Envisat or Topex/Poseidon/ERS) with the same ground track. The data span the period 1993-2011, with a spatial resolution of $1 / 3^{\circ} \times 1 / 3^{\circ}$ and weekly time resolution. All the standard corrections (tides, wet/dry troposphere, and ionosphere) were applied to altimetry data [Benada, 1997]. The atmospheric correction was also applied in order to minimize aliasing effects [Volkov et al., 2007].

[10] Temperature $(T)$ and salinity $(S)$ observations are obtained from the permanent hydrographic station located at Skrova off the Norwegian coast (see Figure 1a). This station provides weekly $T$ and $S$ observations at 14 vertical levels covering the whole water column from top to $300 \mathrm{~m}$ and spanning the period 1950-2011. These data were provided by the Institute of Marine Research, Bergen, Norway. In addition to the station at Skrova, we also use $T$ and $S$ observations from the Ocean Weather Station Mike (OWSM) in the Norwegian Sea (Figure 1a). This station provides $T$ and $S$ observations in the upper $2000 \mathrm{~m}$ for the period 1950 to November 2009 at weekly or higher frequencies.

[11] Besides individual stations, we also use gridded $T$ and $S$ observations obtained from the ENACT/ENSEMBLES version 2a (EN3) objective analysis data set [Ingleby and Huddleston, 2007] made available by the Met Office Hadley Centre (http://www.metoffice.gov.uk/hadobs/en3/). These data are monthly gridded fields with a spacing of $1^{\circ} \times 1^{\circ}$ spanning the period 1950-2011.

\section{Methodology}

[12] Here we briefly review the different components of sea-level change, $\eta$. The pressure $P_{\mathrm{b}}$ at the ocean bottom $z=-H$ can be obtained from integration of the hydrostatic equation [Ponte, 1999]:

$$
P_{b}=g \int_{-H}^{\eta} \rho d z+P_{a} \approx g \rho_{0} \eta+g \int_{-H}^{0} \rho d z+P_{a}
$$

where $g$ is the gravitational acceleration, $P_{\mathrm{a}}$ is the atmospheric SLP, $\rho$ is the in situ density of the water, and $\rho_{0}$ is a reference density $\left(1025 \mathrm{~kg} / \mathrm{m}^{3}\right.$; this is a reasonable approximation as density variations are usually $<1 \%$ compared with mean density). Since we are interested in the anomalies (i.e., deviations from the time-mean fields), we divide variables into a mean part and a fluctuating part:

$$
\begin{gathered}
\rho=\langle\rho\rangle+\rho^{\prime} \\
P_{a}=\left\langle P_{a}\right\rangle+P_{a}^{\prime}
\end{gathered}
$$

where angle brackets denote time average and the prime represents anomalies. Now an equation for the fluctuating quantities can be obtained by taking the difference between equation (1) and its time average:

$$
P_{b}^{\prime}=g \rho_{0} \eta^{\prime}+g \int_{-H}^{0} \rho^{\prime} d z+P_{a}^{\prime}
$$

[13] Equation (3) can be rearranged to obtain an expression for the SLA:

$$
\eta^{\prime}=-\frac{1}{\rho_{0}} \int_{-H}^{0} \rho^{\prime} d z+\frac{P_{b}^{\prime}}{g \rho_{0}}-\frac{P_{a}^{\prime}}{g \rho_{0}}
$$

[14] Next, we define the IB effect anomaly, $\eta_{I B}^{\prime}$, by [Ponte, 1999]

$$
\eta_{I B}^{\prime}=\frac{1}{g \rho_{0}}\left(\bar{P}_{a}^{\prime}-P_{a}^{\prime}\right)
$$

where the overbar denotes spatial average over the global oceans. Note that both $\bar{P}_{a}^{\prime}$ and $P^{\prime}{ }_{a}$ vary in time. We also define the steric component anomaly, $\eta_{S}^{\prime}$, by

$$
\eta_{S}^{\prime}=-\frac{1}{\rho_{0}} \int_{-H}^{0} \rho^{\prime} d z
$$

[15] Finally, we define the mass component of sea level, $\eta_{m}^{\prime}$, by

$$
\eta_{m}^{\prime}=\frac{1}{g \rho_{0}}\left(P_{b}^{\prime}-\bar{P}_{a}^{\prime}\right)
$$

[16] Now equation (4) can be written as

$$
\eta^{\prime}=\eta_{I B}^{\prime}+\eta_{S}^{\prime}+\eta_{m}^{\prime}
$$

[17] The IB effect, $\eta_{I B}^{\prime}$, represents the redistribution of mass within the ocean as a result of changes in the surface atmospheric pressure. In equation (5), values of $\bar{P}_{a}^{\prime}$ are computed for each month using the land-sea mask provided with the NCEP reanalysis. It is worth commenting that tests 
comparing values of $\eta_{I B}^{\prime}$ with and without the term $\bar{P}_{a}^{\prime}$ have shown that $\bar{P}_{a}^{\prime}$ has little effect at the latitudes considered here. This is consistent with the results by Ponte [2006], which showed that the importance of $\bar{P}_{a}^{\prime}$ is confined to tropical latitudes. The IB approximation assumes that there are no ocean currents associated with atmospheric pressure variations. Such approximation can break down for semi-enclosed basins such as the Arctic Ocean but only at short time scales. Proshutinsky et al. [2007] have found significant water transport associated with atmospheric loading in both the Fram and Bering straits at daily or shorter time scales, but no ocean currents were detected at longer time scales.

[18] The steric component of sea level, $\eta_{S}^{\prime}$, represents the effect of expansion and contraction of the water column associated with density changes caused by $T$ and $S$ variations. In order to quantify the relative contribution of $T$ and $S$ changes to sea level, the steric component can be divided (assuming that deviations from the time-mean of the temperature and salinity are small) into a portion due to temperature changes $\left(\eta_{S}^{\prime \text { Heat }}\right)$ and a portion due to salinity changes $\left(\eta_{S}{ }_{S}^{\text {Salt }}\right)$ [Gill and Niiler, 1973]:

$$
\begin{aligned}
& \eta_{S}^{\prime \text { Heat }}=\int_{-H}^{0} \alpha T^{\prime} d z \\
& \eta_{S}^{\prime \text { Salt }}=-\int_{-H}^{0} \beta S^{\prime} d z
\end{aligned}
$$

where $\alpha$ and $\beta$ are the coefficients of thermal expansion and saline contraction, respectively, and $T$ and $S^{\prime}$ represent a deviation with respect to the time-mean of the temperature and salinity, respectively.

[19] Finally, the mass component, $\eta_{m}^{\prime}$, represents sea-level variations related to water mass addition/removal to/from the oceans due to melting/growing of continental ice and hydrology and to mass redistribution within the ocean that is not caused by local atmospheric pressure changes. It is worth mentioning that, since we focus on detrended sealevel, long-term contributions (linear trend) to sea level from vertical land movements as well as from melting land-based ice and thermal expansion of the oceans are not taken into account in the analysis.

[20] Unless otherwise stated, all correlations quoted in this paper are significant at the $95 \%$ confidence level, where we account for the reduction in the effective degrees of freedom (EDOFs) due to the 2 year running mean filter applied. This results in a reduction by a factor of 24 (for monthly time series) in the EDOF [Emery and Thomson, 1998], which needs to be accounted for when estimating the significance of the correlation. Statistical significance is based on $t$ test at the $95 \%$ level.

[21] In addition to correlation, we also use the explained variance, which provides a measure of the agreement between two variables in terms of both variability and magnitude. The percent of variance $(\% \sigma)$ of a variable, $y$, explained by another variable, $\hat{y}$, is computed as follows:

$$
\% \sigma=100\left(1-\frac{\operatorname{var}(y-\hat{y})}{\operatorname{var}(y)}\right)
$$

where the operator $\operatorname{var}()$ denotes variance.

\section{Results}

\subsection{The Contribution of the IB Effect}

[22] Sea-level variations associated with the IB effect are closely related to changes in atmospheric forcing as they represent the response of the ocean to changes in surface atmospheric pressure. Hence, one needs to quantify its contribution and remove it from the total sea-level signal in order to identify the contribution from other mechanisms also linked to atmospheric forcing, such as the effect of wind and that of surface buoyancy fluxes. There have been various studies that have demonstrated a significant contribution of the IB effect to sea-level variability both along the Norwegian coast and in the Siberian Seas. For instance, Proshutinsky et al. [2004] studied the correlation between monthly sea level from tide gauge records located in the Siberian Seas and SLP for the period 1954-1989 and found negative correlations ranging from -0.2 in the East Siberian and Chukchi Seas to -0.7 in the Kara Sea. In another paper, Proshutinsky et al. [2007] found that the IB effect dominates over wind forcing in the Kara Sea, while in the Laptev, East Siberian, and Chukchi Seas, the contribution of wind forcing is larger than that of the IB effect. Regarding the Norwegian coast, Richter et al. [2012a] have found that the IB effect explains between $30 \%$ and $50 \%$ of the low pass-filtered (1 year running mean) sea-level variability at most tide gauge stations along the Norwegian coast. However, they have also found that the contribution of the IB effect is different for different time scales: it dominates sea-level variability on subseasonal time scales and it gradually becomes less important as we move toward longer time scales.

[23] The contribution of the IB effect to sea-level variability (equation 5) is explored here by quantifying the variance of the low pass-filtered sea level explained by the IB effect at each of the six regions according to equation 11 (Table 2 , second column). The average IB effect for each region is estimated by averaging the IB contribution for all tide gauge stations within the same region (the IB contribution for individual tide gauges is taken as that at the nearest grid point), in the same way as we computed the average sea level (see section 2). The largest contribution is found in the Norwegian $(\sim 36 \%)$, Barents $(\sim 38 \%)$, and Kara $(\sim 34 \%)$ Seas. The value found for the Norwegian coast is consistent with the results by Richter et al. [2012a]. The IB effect plays a relatively smaller but significant role also in the Laptev Sea $(\sim 24 \%)$, but it is almost negligible in the East Siberian and

Table 2. Percent of Variance $(\% \sigma)$ of the Low Pass-Filtered (2 Year Running Mean) Average Sea Level Explained by the IB Effect in Six Regions: Norwegian Coast, Barents Sea, Kara Sea, Laptev Sea, East Siberian Sea, and Chukchi Sea (Second Column) ${ }^{\mathrm{a}}$

\begin{tabular}{lrcc}
\hline Region & $\% \sigma$ & AO & SCA \\
\hline Norwegian Sea & 35.5 & $0.60(0.56)$ & $-0.45(-0.32)$ \\
Barents Sea & 38.1 & $0.79(0.66)$ & $-0.47(-0.41)$ \\
Kara Sea & 34.2 & $0.60(0.46)$ & $-0.24^{*}\left(-0.25^{*}\right)$ \\
Laptev Sea & 24.0 & $0.46(0.37)$ & $-0.24^{*}\left(-0.24^{*}\right)$ \\
East Siberian Sea & 0.1 & $0.18^{*}\left(0.17^{*}\right)$ & $-0.25^{*}\left(-0.24^{*}\right)$ \\
Chukchi Sea & 0.1 & $0.27^{*}\left(0.28^{*}\right)$ & $-0.53(-0.47)$ \\
\hline
\end{tabular}

${ }^{\mathrm{a}}$ The correlation between the average sea level in each region and both the AO (third column) and the SCA (last column) indices is also shown. Values within the parenthesis correspond to the correlation after correcting for the IB effect. The asterisk $(*)$ indicates nonsignificant values. 
Chukchi Seas $(\sim 0 \%)$. It is worth mentioning that correlations between sea level and the IB effect in the East Siberian and Chukchi Seas are nonsignificant at the time scales considered here. A comparison between sea level before and after correcting for the IB effect (Figure 2) shows that many of the major features remain the same after the correction. For instance, in the Norwegian Sea, the peaks observed in 1967, 1983, and 1989 are reduced by about $2 \mathrm{~cm}$ after correcting for the IB effect but they are still very prominent. Our results in the Siberian Seas are in good agreement with the findings by Proshutinsky et al. [2004, 2007].

[24] In order to further explore the relationship between sea level and changes in surface atmospheric pressure, we also compare smoothed (2 year running mean) values of the AO index (National Weather Service Climate Prediction Center, http://www.cpc.noaa.gov) and the average sea level in the six regions before and after correcting for the IB effect (Table 2, third column). We find significant positive correlation between the sea level not corrected for the IB effect and the AO index in all regions except in the East Siberian and Chukchi Seas, although its magnitude differs from one region to another. The largest correlation in the Arctic Ocean is found in the Barents Sea (0.79), and it decreases gradually from there toward the Chukchi Sea where it becomes nonsignificant. In the Norwegian coast, the correlation is statistically significant with a value of 0.60 . It is worth noting that the values of the correlation shown in Table 2 are computed for the longest period for which sea-level data are available in each region (see Table 1). When correlations are calculated over the period 1951-1995 (similar to the period for the Barents Sea), they increase significantly in all regions. Their values are $0.76,0.66,0.60$, and 0.47 in the Norwegian Coast and the Kara, Laptev, and East Siberian Seas, respectively. This implies that the correlation with the AO index is not only spatially but also temporally variable. This confirms the result found in previous related

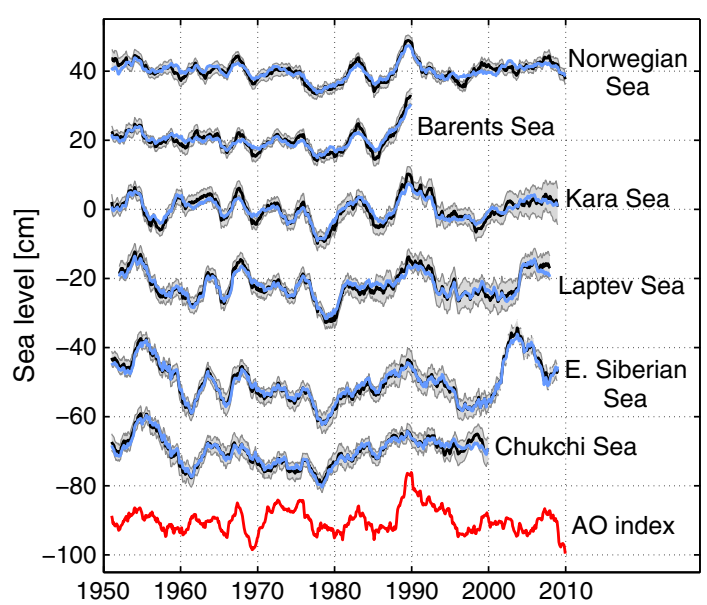

Figure 2. Low pass-filtered (2 year running mean) time series of total (black line) and IB-corrected (blue line) sea level in six regions: Norwegian coast, Barents Sea, Kara Sea, Laptev Sea, East Siberian Sea, and Chukchi Sea. The AO index (red line) is also shown (scaled to have the same standard deviation as the average of the sea-level time series). The gray shaded area represents the uncertainty of the time series of total sea level. studies [Proshutinsky et al., 2007; Henry et al., 2012] that the correlation between sea level and the AO index in the Siberian Seas is significant for the years before 1995 but it declines rapidly after this year. Finally, we have compared the low pass-filtered sea level with other climatic indices, namely, the North Atlantic Oscillation, the East Atlantic Pattern, the West Pacific Pattern, the East Pacific/North Pacific Pattern, the Pacific/North American Pattern, the East Atlantic/West Russia Pattern, the Scandinavia Pattern (SCA), and the Pacific Decadal Oscillation (National Weather Service Climate Prediction Center, http://www. cpc.noaa.gov). We have found significant (although smaller than for the AO index) negative correlations with the SCA index (Table 2, last column) but much smaller or nonsignificant correlations for all the other indices (not shown).

[25] After correcting for the IB effect, we find that the correlation between sea level and the AO index is slightly reduced but it remains significant in all regions except in the East Siberian and Chukchi Seas (Table 2, third column). The implication of this is that there is a contribution from the large-scale atmospheric forcing associated with the AO that is due to mechanisms other than the IB effect. It is also worth mentioning that, after correcting for the IB effect, the negative correlation with the SCA index remains significant in all regions where it was significant before the correction.

[26] Large-scale atmospheric changes can affect sea level through a variety of mechanisms (besides the IB effect). Changes in either wind stress curl (WSC) or buoyancy fluxes can produce ocean circulation changes, which are accompanied by water mass and heat redistributions and, consequently, sea-level changes. Changes in surface buoyancy fluxes and in wind stress (via Ekman pumping and heat advection) can also produce local steric sea-level changes. At the coast, there is an additional response of the ocean to longshore wind forcing, resulting from the fact that there can be no flow normal to the coast so a convergence or divergence is established with a corresponding change in sea level. The response will include changes in both the mass and the steric components, consisting respectively of a piling up of water on the coast and vertical movements of the thermocline. This and other mechanisms are explored in the next sections.

\subsection{Regional Coherence of IB-Corrected Sea Level}

[27] Since sea-level variability appears to be related to changes in the large-scale atmospheric forcing over the North Atlantic and Arctic regions, evidenced by the correlation with the $\mathrm{AO}$, it is reasonable to expect a certain degree of sea-level coherence between regions. It is important to note that because the correlation between sea level and the IB effect is very low in some regions (i.e., East Siberian and Chukchi Seas), applying the IB correction may impose a coherent signal on the residual time series if the IB signal was comparable in magnitude to the sea level. However, as commented in section 4.1, differences between the uncorrected and corrected sea level (Figure 2) are very small in all regions. The IB correction reduces some of the peaks by about 2 or $3 \mathrm{~cm}$, but all major features remain unchanged after the correction.

[28] Examining Figure 2 shows that the decadal sea-level variability is significant in all regions, but most notably in the Laptev, East Siberian, and Chukchi Seas where decadal 
fluctuations with peak amplitudes larger than $20 \mathrm{~cm}$ are observed. Although many features are common to all regions, such as the low in 1978 and the sea-level rise between 1979 and 1990, significant differences among regions are also evident. In general, sea-level variability is highly coherent from Norway to the Kara Sea, and also between the East Siberian and Chukchi Seas. The Laptev Sea shows similarities with both the Kara and the East Siberian Seas, although its major features are more similar to those of the East Siberian Sea, at least up to about 2000. It is worth noting that the good agreement between sea level in the Laptev Sea and that in the East Siberian Sea disappears after 1999, which suggests that some components of the interdecadal forcing may have become important in recent years. A remarkable feature is the substantial sea-level increase $(\sim 22 \mathrm{~cm})$ in the East Siberian Sea between 2000 and 2003 and the considerable decline $(\sim 15 \mathrm{~cm})$ between 2004 and 2008. This feature is not reflected in the AO index. We also note that this feature is unique to the East Siberian Sea and it is responsible for the absence of correlation between the East Siberian and Laptev Seas after 1999. While a sealevel increase is observed between 2002 and 2004 in the Laptev Sea, its magnitude $(\sim 12 \mathrm{~cm})$ is almost half of that in the East Siberian Sea. In the Kara Sea, a sea-level increase of $\sim 5 \mathrm{~cm}$ is observed between 2000 and 2005 .

[29] In order to quantify the coherence of the sea-level variability among regions, we have computed the cross correlation between the low pass-filtered time series of sea level in the six regions for the period before 2000 (Figure 3a). This analysis has been performed for both the IB-corrected and uncorrected sea level. Overall, no significant differences between the uncorrected and corrected sea level are found in terms of cross correlations, which further confirms that no correlation is imposed when correcting for the IB effect. Correlations between regions are significant for all pairs of time series. As expected from the preceding discussion of Figure 2, we identify two large regions of high coherence with cross correlations above 0.7: a region that includes the Norwegian coast and the Barents and Kara Seas, and another region that covers the Laptev, East Siberian, and the Chukchi Seas. The two areas of coherence are even more evident when computing the cross correlation for the summer values (JJAS) (Figure 3b), when sea ice is at its minimum extent, and thus, the interaction between ocean and atmospheric forcing (i.e., wind) is larger. For winter values (DJFM) (not shown), the cross-correlation pattern is similar to that for whole-year and summer values but with correlation values generally smaller.

[30] Considering the above results, we will analyze observed sea-level variability by areas with high cross correlations. In section 4.3, we will examine the Norwegian coasts and the Barents and Kara Seas, which appear to be affected by a similar mechanism, and in section 4.4, we will focus our attention on the Laptev, East Siberian, and Chukchi Seas. Because the contribution of the IB effect has already been discussed in this and the previous sections, in the following sections, we will focus on the IB-corrected sea level. Hence, hereinafter and unless otherwise stated, whenever we refer to sea level, we will implicitly refer to the IB-corrected sea level.

\subsection{Sea-Level Variability in the Norwegian, Barents, and Kara Seas}

\subsubsection{The Steric and Mass Components of Sea Level}

[31] After correcting for the IB effect, sea level can be considered the sum of two terms: the steric and mass components (see equation 8). In this section, we quantify and explore the contribution of the steric component using equation 6 . It is important to note here that, due to the existence of the Norwegian Atlantic Current (NwAC) along the Norwegian coast, the estimate of the steric component at the tide gauges is very sensitive to the location where the $T$ and $S$ observations used in the steric computation have been taken. Bingham and Hughes [2012] have shown that the existence of slope currents (especially on western boundaries and at high latitudes on eastern boundaries) results in the decoupling of coastal and deep ocean sea level. Clearly, and because of the aforementioned decoupling, steric estimates based on $T$ and $S$ measurements made on the western side of the NwAC will not be representative of the sea level at the tide gauges on the eastern side. Hence, we decide to use $T$ and $S$ observations from the hydrographic station at Skrova (Figure 1a). This station neither is on the west side of the NwAC nor is located in too shallow water (where the steric signal would be too small) as it covers from top to $300 \mathrm{~m}$ depth; hence, it is expected to provide a reasonable estimate of the steric component at the tide gauges. (a)

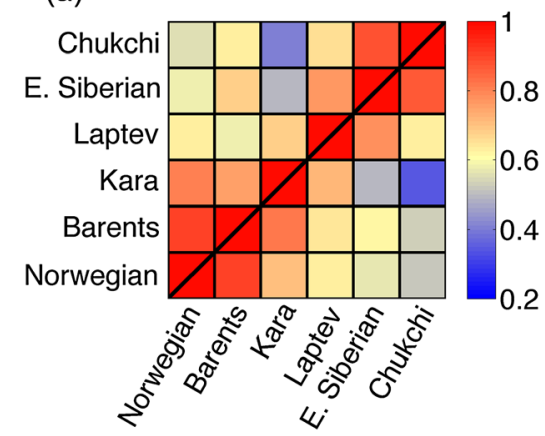

(b)

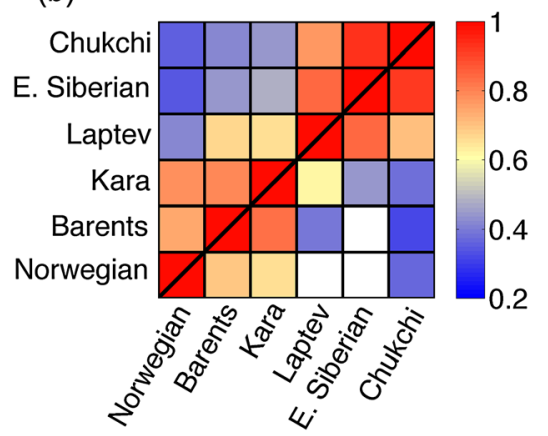

Figure 3. (a) Cross correlation between the low pass-filtered time series of sea level in the six regions for both the non-IB-corrected (lower triangle) and the IB-corrected (upper triangle) sea level. (b) Same as Figure $3 \mathrm{a}$ but for summer values. White squares indicate nonsignificant correlation. 
[32] Figure 4 shows a comparison between the steric component at Skrova and the IB-corrected sea level from the tide gauge record at Narvik (the closest tide gauge to Skrova). The agreement between the two time series is very good with a correlation of $\sim 0.82$. The percent of variance of the sea level from the tide gauge record explained by the steric component is $61 \%$. We have also computed the explained variance for the sea level averaged over the nine tide gauge records on the Norwegian coast, which is very similar $(62 \%)$ to that for the tide gauge at Narvik. This result implies that a considerable fraction of the IB-corrected sea-level variability is driven by the steric component. This is consistent with the results of Richter et al. [2012a], which showed a significant contribution of the steric component to sea level along the Norwegian coast, but contrasts somehow with the results by Henry et al. [2012] who found no significant correlation at inter-annual time scales (for the detrended time series) for the period 1970-2010. The reason for this apparently contradictory results may be due to the fact that Henry et al. [2012] estimated the steric component from interpolated $T$ and $S$ products, which generally use a radius of several hundred kilometers for the interpolation of the $T$ and $S$ profiles onto a regular grid. In consequence, the grid points covering the continental shelf in the interpolated products are likely to include $T$ and $S$ profiles located on the western side of the NwAC, which may provide information that is not representative of the sea level at the tide gauges. In order to confirm this, we have estimated the steric sea level on the Norwegian coast using $T$ and $S$ observations from the EN3 interpolated product. We have found no significant correlation between the low pass-filtered ( 2 year running mean) and detrended sea level on the Norwegian coast and the steric component from the EN3 data set.

[33] Finally, we have also computed the thermosteric and halosteric contributions using equations (9) and (10), respectively. We find that the thermosteric contribution explains about $44 \%$ of the variability of the low pass-filtered (2 year running mean) sea level from the tide gauge record at Narvik, whereas the halosteric contribution explains about $10 \%$ of the variability. In the following sections, we investigate possible mechanisms that can produce changes in both the steric and the mass components of sea level, and hence can explain part of the observed sea-level variability.

\subsubsection{The Effect of the Wind}

[34] Sea level along the Norwegian coast is strongly affected by variations in the NwAC [e.g., Richter et al., 2012b].

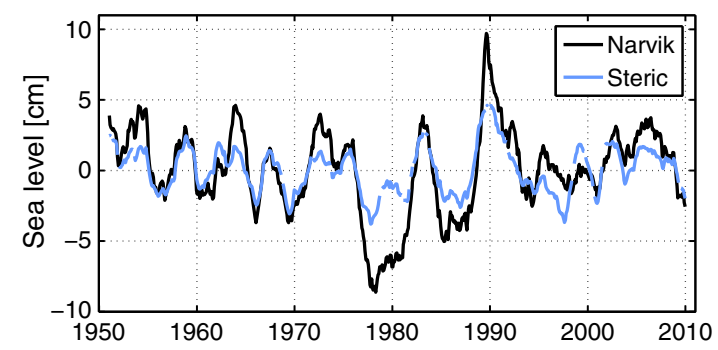

Figure 4. Comparison of the steric sea level (blue line) referenced to $300 \mathrm{~m}$ computed using $T$ and $S$ observations from the hydrographic station at Skrova and the sea level (black line) from the tide gauge record at Narvik. A 2 year running mean has been applied to both time series.
The NwAC is a poleward extension of the Gulf Stream and represents a conduit for the poleward flux of relatively warm and saline Atlantic water from the North Atlantic to the Arctic Ocean [Orvik and Skagseth, 2005]. Changes in the NwAC affect sea level at the coast mainly through the associated changes in the barotropic pressure gradient normal to the flow to maintain a geostrophic balance, but also through changes in the steric height due to variations in the transport of warm and saline Atlantic water. Indeed, previous studies have found a significant correlation between the variability of the NwAC across the Svinøy section west of Norway (hereafter referred to as the Svinøy current) and an indirect measure of the transport derived from the local cross-slope sea-level gradient estimated from either satellite altimetry or tide gauges [Skagseth et al., 2004; Richter et al., 2012b].

[35] It is well established that the variability of the Svinøy current is largely driven by wind forcing over the region [Skagseth et al., 2004; Richter et al., 2012b]. Hence, we now focus our attention on the contribution of the wind to coastal sea-level variability along the Norwegian coast. Since wind variability is closely related to atmospheric pressure variations, it is useful to begin by identifying the large-scale SLP pattern associated with the coastal sea-level variability. To achieve this, we perform a canonical correlation analysis (CCA) with prefiltering [Barnett and Preisendorfer, 1987] between the SLP over a region covering the North Atlantic and the Nordic Seas $\left(60^{\circ} \mathrm{W}-35^{\circ} \mathrm{E}, 40^{\circ} \mathrm{N}-75^{\circ} \mathrm{N}\right)$ and the sea level from the nine tide gauge stations located along the Norwegian coast (see Figure 1a). The CCA detects the patterns in both data sets that share maximum correlation of their canonical correlation coefficients. The CCA has been applied to the low pass-filtered (2 year running mean) time series.

[36] Figure 5a shows the leading CCA pattern of the SLP (37\% variance explained) together with the regression of the wind stress field on the canonical coefficient vector associated with the leading CCA pattern (the sign of the CCA pattern has been chosen so that the correlation between sea level and the canonical coefficient vector is positive). The leading CCA pattern bears a striking resemblance to the loading pattern of the AO. Indeed, the associated canonical coefficient vector is highly correlated (0.88) with the AO index. This pattern also resembles the leading empirical orthogonal function (EOF) of the SLP over the same region found by Richter et al. [2012b], which they related to variations in the transport of the Svinøy current. We also note that the wind blows parallel to the continental slope with the coast to its right, from Ireland to northern Norway, thus producing an Ekman transport toward the coast. This causes water to pile up on the coast and also downwelling (i.e., the thermocline is pushed down; hence, the steric sea level rises). A coastal current in geostrophic balance with the sea-level field is also generated, this being in the same direction as that of the wind. Hence, an increase (decrease) in the strength of the wind will cause sea level to rise (fall) at the coast and the NwAC to strengthen (weaken).

[37] It is important to note, however, that the response of sea level may not be purely local since fluctuations of the thermocline produced by the longshore wind can propagate along the coast in the same direction as coastal Kelvin waves (with the coast to the right in the Northern Hemisphere) [Gill, 1982]. This means that the effect of the longshore 
(a)

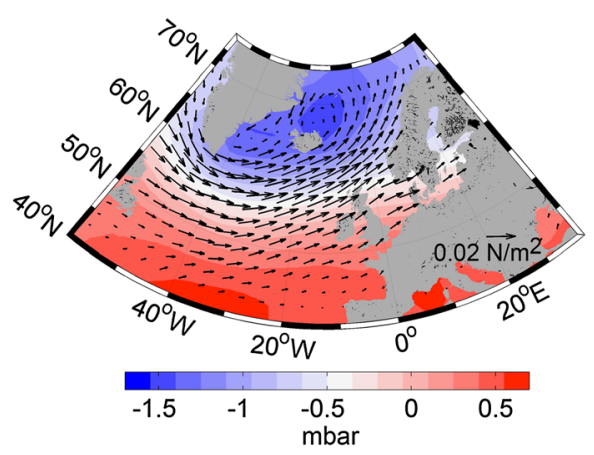

(b)

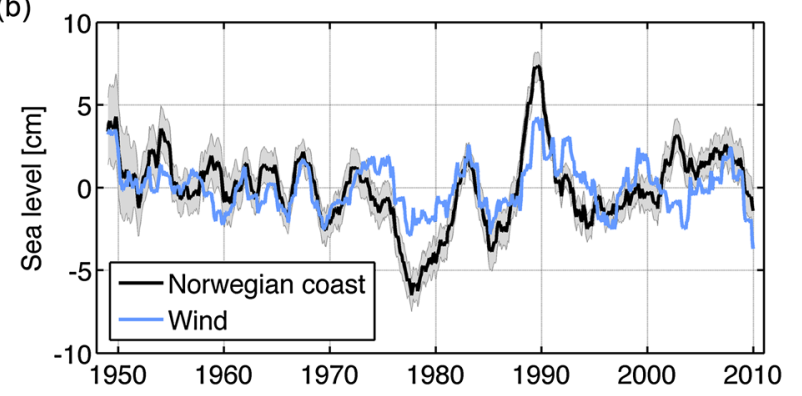

Figure 5. CCA between SLP and the sea level from nine tide gauge stations along the Norwegian coast. (a) The leading CCA pattern of the SLP (37\% explained variance) in units of mbar per standard deviation of the first canonical coefficient vector (CCV1). The wind stress field that regressed onto the standardized CCV1 is also shown (a reference vector is shown in the bottom-right corner). (b) The average of sea level at nine tide gauge stations on the Norwegian coast (black line) and the longshore wind (blue line) over the Faroe-Shetland channel and the Norwegian continental shelf that regressed on the sea level.

wind is cumulative along the coast following the direction of Kelvin wave propagation. Hence, to properly quantify the contribution of the wind to the sea-level variability along the Norwegian coast, we integrate the longshore wind stress from the western coast of Ireland up to the Norwegian coast (up to $67^{\circ} \mathrm{N}$ ). This is done first by projecting the wind stress field onto the direction of the $400 \mathrm{~m}$ depth contour from Ireland to Norway and then by adding all the projected wind stress vectors blowing over the continental shelf shallower than $400 \mathrm{~m}$. Figure $5 \mathrm{~b}$ shows a comparison between the average sea level along the Norwegian coast and the integrated longshore wind regressed onto the time series of sea level. Overall, there is good agreement between the two time series with a correlation coefficient of 0.62 (significant at the $99 \%$ confidence level). The integrated wind shows peaks in 1983 and 1989 and a dip in 1978 in agreement with the sea level; however, the magnitude of those features appears to be weaker than in the sea level, suggesting that additional mechanisms are important. This is consistent with the results by Richter et al. [2012b], who performed an EOF analysis of SLP and sea level from satellite altimetry over the Nordic Seas and found a correlation of 0.60 between the principal component (PC) of the first mode of SLP and the PC of the sea-level mode associated with the variability of the Svinøy current. The value of the correlation suggests that wind forcing, and more specifically longshore wind, explains much but not all of the sea-level variability.

\subsubsection{A Link With the Eastern Boundary of the North} Atlantic

[38] In a recent paper, Calafat et al. [2012a] have shown that decadal sea-level variability on the eastern boundary of the North Atlantic is mostly driven by the poleward propagation of wind-driven sea-level fluctuations along the coast. Evidence for large-scale coherent sea-level signals and wave propagation along a boundary has also been found in the Arctic Ocean, the North Pacific, and the west coast of South America [Enfield and Allen, 1980; Chelton and Davis, 1982; Clarke and Lebedev, 1999; Hughes and Meredith, 2006]. Because boundary waves propagate poleward along an eastern boundary, one would expect the large-scale coherent sea-level signal found by Calafat et al. [2012a] to propagate further north across the Greenland-Scotland Ridge into the Norwegian Sea, hence affecting also sea level along the Norwegian coast.

[39] Figure 6 shows the correlation of the low passfiltered SLA from satellite altimetry at each grid point with SLA averaged along a short section along the continental slope near the Irish-Scottish coast. We note that higher correlations are found predominantly along the slope, consistent with the existence of a propagating sea-level signal. Moreover, it shows that the coherent sea-level signal extends all the way to the Norwegian coast and also to Iceland, always along the slope. This result supports our hypothesis that part of the sea-level variability on the Norwegian coast may be related to the large-scale coherent signal found by Calafat et al. [2012a] on the eastern boundary of the North Atlantic. However, it remains to be seen how large this contribution may be.

[40] To quantify the contribution of the mechanism described above, we compare the IB-corrected sea level from the tide gauge at Newlyn (on the eastern boundary of the North Atlantic; see Figure 1a) with the sea level in the Norwegian Sea. The reasons for using Newlyn as a proxy for the sea level on the eastern boundary of the North Atlantic are twofold: (1) Calafat et al. [2012a] showed that the effects of the longshore wind and wave propagation are well captured by Newlyn; (2) as commented in section 4.3.2, the effects of the longshore wind are cumulative along the coast following the direction of propagation of Kelvin waves. This means that sea-level variations observed at a

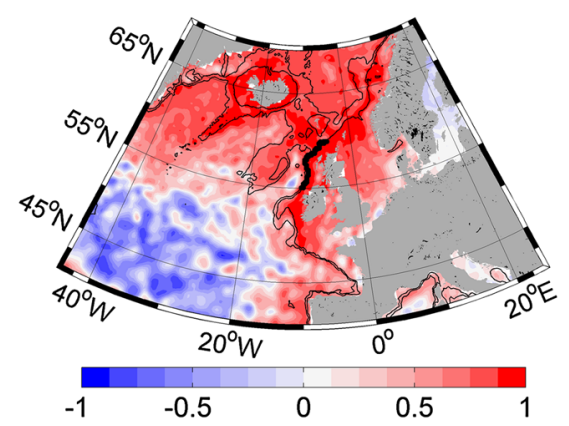

Figure 6. Correlation of the low pass-filtered (2 year running mean) SLA from satellite altimetry at each grid point with SLA averaged along the section of the slope denoted by the black thick line. Depth contours at 400 and $1500 \mathrm{~m}$ are also shown. 
particular latitude continue to be forced by the wind while propagating northward, and thus, the best approach is to use a tide gauge located on the eastern boundary of the North Atlantic but as far north as possible so that it better represents the signal that propagates further north into the Norwegian Sea. The correlation between sea level at Newlyn and that in the Norwegian Sea is 0.55 (significant at the 99\% confidence level) for the period 1948-2010. We also note that the sea level at Newlyn shows no significant correlation with the integrated longshore wind along the Norwegian shelf as computed in section 4.3.2, which indicates that the effect of the longshore wind and the propagation of the sea-level signal along the eastern boundary of the North Atlantic are independent mechanisms. Hence, the next step is to add both contributions and compare the result with the sea level on the Norwegian coast. To combine the two contributions, we add the integrated longshore wind along the Norwegian coast (i.e., the time series presented in Figure 5b) to the sea level from the tide gauge at Newlyn. Figure 7 shows a comparison between this combination and the average sea level along the Norwegian coast. The agreement between the two time series is very good, supporting our hypothesis that sea-level variability along the Norwegian coast is driven partly by the propagation of sea-level fluctuations along the eastern boundary of the North Atlantic and partly by the wind over the Faroe-Shetland channel and the Norwegian shelf. The reconstruction reproduces not only the major features, such as the peaks in 1983 and 1989 and the dip in 1978, but also their right magnitude. The correlation between the two time series increases to 0.84 from 0.55 after including the effect of longshore winds. The variance of the sea level along the Norwegian coast explained by the combination of the two mechanisms is $\sim 71 \%$. The correlation between the sea level and the reconstruction is also highly significant in the Barents (0.76) and Kara Seas (0.72), suggesting that the signal propagates further north into the Barents Sea and, ultimately, also into the Kara Sea.

[41] To further confirm the existence of a signal of Atlantic origin, we have carried out a complementary test. Examining Figure 6 shows that the tide gauge at Torshavn (see Figure 1a) may be also affected by the coherent signal of the Eastern North Atlantic. However, because it is located on the western side of the NwAC, the residual sea-level

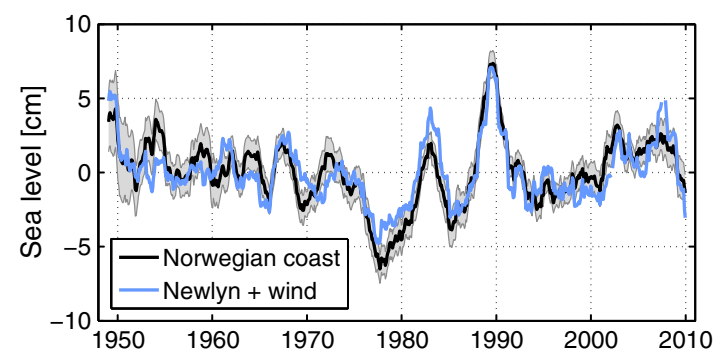

Figure 7. The average of sea level at nine tide gauge stations along the Norwegian coast (black line) and a reconstruction of sea level (blue line) using a combination of the tide gauge at Newlyn (on the eastern boundary of the North Atlantic) and the longshore wind as shown in Figure 5b. The gray shaded area represents the uncertainty of the time series of the sea level along the Norwegian coast. A 2 year running mean has been applied to both time series. signal resulting from the removal of the propagating signal from this tide gauge record is expected to be more related to the sea-level variability in the interior of the Norwegian Sea (which is also on the western side of the NwAC) than to the sea level on the Norwegian coast (see Figure 1a for details on the bathymetry of the region). Hence, here we hypothesized that the sea level at Torshavn is a combination of the coherent signal propagating along the eastern boundary of the North Atlantic and a more local contribution related to the sea-level variability in the deep parts of the Norwegian Sea.

[42] To confirm the validity of our hypothesis, we need to obtain an estimate of the sea-level variability in the Norwegian Sea. This is achieved by computing the steric component of sea level referenced to $2000 \mathrm{~m}$ at OWSM (see Figure 1a) using equation (6). Because OWSM is located on the western side of the NwAC and provides $T / S$ observations covering almost the whole water column from top to $2000 \mathrm{~m}$, it is expected to provide a good estimate of the sea-level variability in the Norwegian Sea. The correlation between the tide gauge record at Torshavn and the steric component at OWSM is 0.60 for the period 1958-2006. If we add the sea level at Newlyn to the steric component at OWSM, the correlation between the resulting time series and the sea level at Torshavn increases to 0.82. A comparison between the two time series is shown in Figure 8 . We note that the agreement between the two time series is good in terms not only of variability but also of its magnitude, which further confirms our initial hypothesis.

\subsection{Sea-Level Variability in the Laptev, East Siberian, and Chukchi Seas}

\subsubsection{The Vorticity Index and the Longshore Wind}

[43] It is well established that a significant fraction of the sea-level variability in the Laptev, East Siberian, and Chukchi Seas is related to wind forcing [Proshutinsky et al., 2004, 2007]. However, there are certain features of the inter-annual sea-level variability exhibited by the tide gauge records that remain unexplained, either because the models did not reproduce them or due to significant discrepancies between models. One of those features is the sea-level variability after 1999. We note that Proshutinsky et al. [2007, Figure 1] found a sea-level rise of $\sim 6 \mathrm{~cm}$ for the period 2000-2004, which is significantly smaller than the sea-level increase of $\sim 22 \mathrm{~cm}$ that we have found in the East Siberian Sea between 2000 and 2003. This is due to

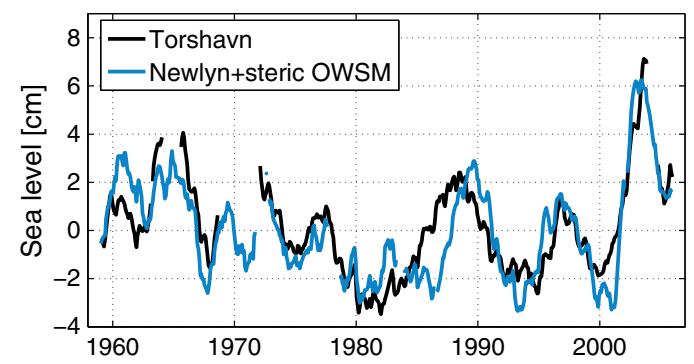

Figure 8. Comparison of the sea level at Torshavn (black line) and the sum of the steric sea level computed using $T$ and $S$ observations from OWSM and the sea level from the tide gauge record at Newlyn (blue line). A 2 year running mean has been applied to both time series. 
the fact that the sea-level time series shown in Figure 1 of Proshutinsky et al. [2007] was obtained by averaging sea level for nine tide gauge stations located in the Kara and Laptev Seas. We have shown in section 4.2 that sea level increased by only $\sim 5 \mathrm{~cm}$ between 2000 and 2005 in the Kara Sea and by $\sim 12 \mathrm{~cm}$ between 2002 and 2004 in the Laptev Sea; both increases are much weaker than the increase in the East Siberian Sea. Another interesting feature presented in this study is the rapid decline in sea level $(\sim 15 \mathrm{~cm})$ between 2004 and 2008 in the East Siberian Sea. None of the above features are reflected in the AO index. In fact, the AO index fails to reproduce many of the major features observed during the period 1950-2009 in the Laptev, East Siberian, and Chukchi Seas. Our aim in this section is to propose a better descriptor of the observed sea-level variability (IB corrected) in those regions over the whole period 1950-2009.

[44] The Laptev and East Siberian Seas are located in a region of the Arctic Ocean that coincides with the position of the zero WSC line (see Figure 10), marking the confluence of two predominant large-scale centers of atmospheric circulation over the Arctic Ocean [Johnson and Polyakov, 2001]. Previous studies have shown that, due to the particular position of the two basins, their water mass properties are very sensitive to the shifts of the zero WSC line or, equivalently, to the shifts between cyclonic or anti-cyclonic atmospheric circulation over the region [Dmitrenko et al., 2005; Dmitrenko et al., 2008; Dmitrenko et al., 2011]. In particular, these studies have shown on the basis of a vorticity index that periods of predominantly cyclonic atmospheric circulation coincide with an increase of the freshwater content and a decrease of the salinity over the Laptev and East Siberian Sea shelves and vice versa for periods of predominantly anti-cyclonic circulation. In view of these results, and because sea-level variability is closely related to changes in hydrography, we hypothesize that sea-level variability in the Laptev, East Siberian, and Chukchi Seas may also be explained, at least partly, by the shifts between cyclonic and anti-cyclonic atmospheric circulation over those regions.

[45] Following Dmitrenko et al. [2008], we use a vorticity index to characterize changes in atmospheric circulation over the Laptev and East Siberian Seas. Here the index is defined as the average of the WSC over a region north of the New Siberian Islands $\left(138^{\circ} \mathrm{E}-141^{\circ} \mathrm{E}, 77^{\circ} \mathrm{N}-79^{\circ} \mathrm{N}\right)$. Averaging the WSC over slightly different regions resulted essentially in the same vorticity index, as long as the selected region was reasonably close to the zero WSC line in the time-mean pattern of the WSC. A positive (negative) vorticity index corresponds to a cyclonic (anti-cyclonic) atmospheric circulation. Figure 9a shows a comparison between the vorticity index and the sea level in the Laptev, East Siberian, and Chukchi Seas. The agreement between the time series of the sea level and that of the vorticity index is very good in all regions over almost the whole period, but the good agreement appears to break down after 2000 in the Laptev Sea and after 2002 in the East Siberian Sea. In the East Siberian Sea, the vorticity index reproduces much of the sea-level increase between 2000 and 2002, but after 2002, sea level and the vorticity index seem to be in opposite phase. Correlations between the vorticity index and the sea level in the Laptev, East Siberian, and Chukchi Seas for (a)

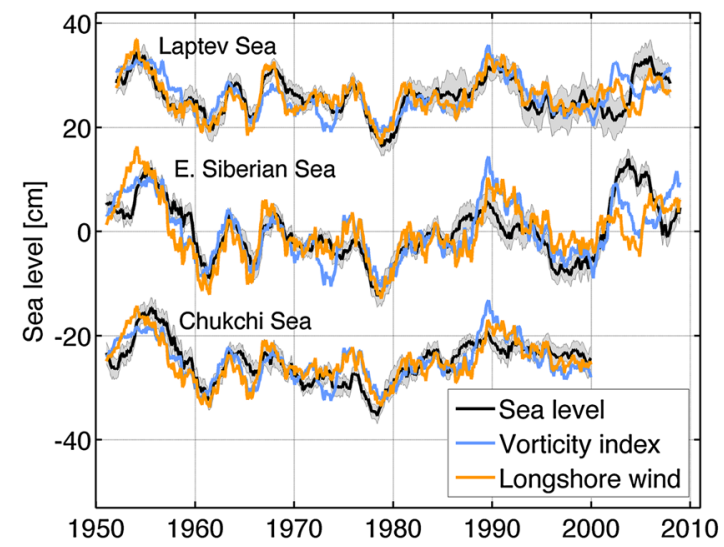

(b)

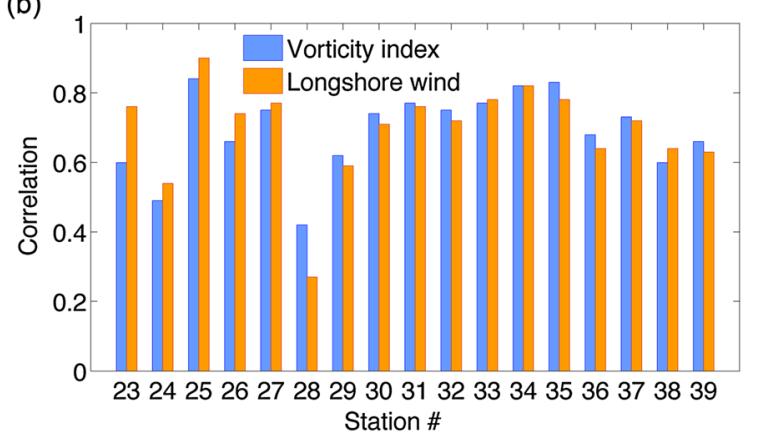

Figure 9. (a) Comparison of the average IB-corrected sea level (black line) in the Laptev, East Siberian, and Chukchi Seas with both the vorticity index (blue line) and the longshore wind (orange line). A 2 year running mean has been applied to all time series. (b) Correlation between the low pass-filtered sea level (IB-corrected) from individual tide gauge records and both the vorticity index (blue) and the longshore wind (orange). Numbers on the $x$ axis correspond to the tide gauge stations shown in Table 1.

the period $1950-1999$ are $0.79,0.81$, and 0.73 , respectively. In order to further quantify the relationship between the vorticity index and the sea level, we have computed their correlation at individual tide gauges in the Laptev, East Siberian, and Chukchi Seas also for the period before 2000 (Figure 9b). Correlations are highly significant $(\geq 0.70)$ at most tide gauge stations. The lowest correlation $(\sim 0.43)$ is found at Zhohova, which is located on an open sea island, where the response of the ocean to wind forcing tends to be smaller.

[46] The good agreement between the vorticity index and the observed sea-level variability suggests that changes in sea level before 2000 are indeed closely related to the shifts between cyclonic and anti-cyclonic atmospheric circulation over the eastern Siberian Seas. However, the mechanisms through which this relationship is established are numerous. For instance, the strong negative correlation between salinity anomalies and the vorticity index found in the previous studies [Dmitrenko et al., 2005; Dmitrenko et al., 2008; Dmitrenko et al., 2011] implies that whenever the vorticity index increases (decreases), sea level also increases (decreases) due to an increase (decrease) in the steric component of sea level induced by a decrease (increase) in salinity. 
Previous studies also found significant correlation between the vorticity index and both ice retreat and freshwater content anomalies [Dmitrenko et al., 2008]. Changes in these two variables can also induce sea-level changes. In addition to those mechanisms, changes in the wind forcing associated with changes in the atmospheric circulation can also produce sea-level changes through Ekman transport toward or away from the coast and upwelling/downwelling. Discriminating the contribution of the mass and densityrelated components of sea level is a difficult task in those regions of the Arctic as topography exerts a strong influence on the density field [Bingham and Hughes, 2012]. This topographic influence needs to be taken into account when estimating the density-related component of sea level at the tide gauges. However, the limited $T$ and $S$ data available in the region make this task almost impossible. It is worth commenting that results by Pavlov [2001] using an ocean model showed that, at decadal time scales, the steric component dominates sea-level changes in the Laptev, East Siberian, and Chukchi Seas.

[47] One thing that we can do is to investigate if changes in the longshore wind show good agreement with sea-level variability. Figure 10 shows the anomaly of SLP and wind stress over the Laptev and East Siberian Seas associated with years of positive and negative vorticity index. We note that during years of positive vorticity index, the low SLP center located over the Barents and Kara Seas strengthens and the high SLP center in the western Arctic Ocean weakens, resulting in a cyclonic atmospheric circulation over the Laptev and East Siberian Seas, while during years of negative vorticity index, the opposite occurs. Examining the wind patterns shows that, during years of positive vorticity index, there are eastward wind anomalies parallel to the coast (i.e., with the coast to its right) in the Laptev Sea and north-eastward in the East Siberian Sea, resulting in anomalies in the Ekman transport toward the coast and probably downwelling (or weaker upwelling), which in turn leads to a sea-level increase on the coast. The situation during years of negative vorticity index is remarkably different, with westward longshore wind anomalies now (or southwestward in the East Siberian Sea), and hence Ekman transport anomalies away from the coast, upwelling, and a decrease in sea level on the coast.

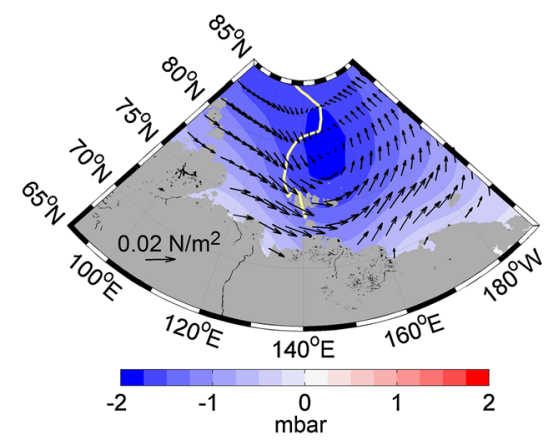

[48] In order to quantify the role of the wind, we have computed estimates of the longshore wind in the Laptev, East Siberian, and Chukchi Seas. Time series of the longshore wind have been produced by averaging the longshore wind over the continental shelf shallower than $400 \mathrm{~m}$ for each region. A comparison between the longshore wind and the sea level is shown in Figure 9. The variability exhibited by the longshore wind is very similar to that of the vorticity index in all regions. The longshore wind is in very good agreement with the sea level for the period 1950-1999, with correlations of $0.88,0.78$, and 0.74 in the Laptev, East Siberian, and Chukchi Seas, respectively. It is interesting to note that, in the Laptev Sea, the longshore wind performs better than the vorticity index, whereas in the other two regions, the longshore wind and the vorticity index show similar correlation with sea level. This is also evident when looking at the correlation between the longshore and sea level at individual tide gauge station (Figure 9b). Finally, it is worth noting that, just like for the vorticity index, the good agreement between the longshore wind and sea level disappears after 2000 in the Laptev Sea and after 2002 in the East Siberian Sea.

\subsubsection{Sea Level After 2002 and the Role of the Beaufort Gyre}

[49] In section 4.4.1, we have shown that the good agreement between sea level and both the vorticity index and the longshore wind in the East Siberian Sea disappears after 2002. In particular, during 2003, sea level continues to increase despite a declining trend in both the vorticity index and the longshore wind, and from 2004 to 2008, sea level falls rapidly $(\sim 15 \mathrm{~cm})$, whereas both the vorticity index and the longshore wind show a positive trend. This suggests that some component of interdecadal forcing may have become dominant after 2003. Changes in GMSL may be one of those factors. To explore this possibility, we have computed the GMSL from satellite altimetry and compared it with the sea level in the East Siberian Sea for the period 2000-2009 with no success. Because the rate of global sea-level change as computed from satellite altimetry does not indicate a global change that can justify the sea-level change in the Siberian Seas, regional forcing must be considered.

[50] Since the East Siberian Sea is located in the eastern side of the Lomonosov Ridge in the Amerasian basin

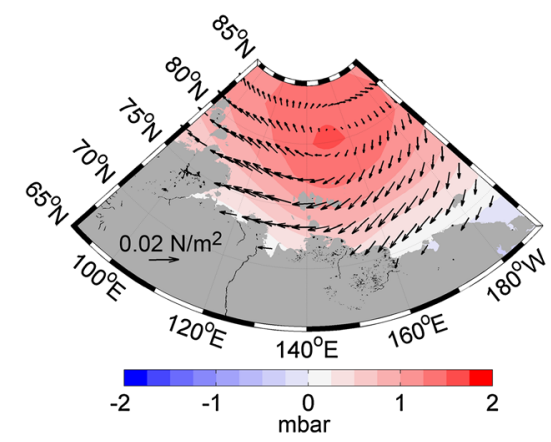

Figure 10. Map showing the anomaly of SLP over the Laptev and East Siberian Seas associated with years of highly positive (left) and negative (right) vorticity index. The associated wind stress anomaly is also shown (a reference vector is shown in the bottom-left corner). Highly positive (negative) years are defined as those years when positive (negative) values of the vorticity index exceed one standard deviation over the period 1950-2009. The yellow line (left map) indicates the zero WSC line in the time-mean pattern of the WSC. 
(see Figure 1b), another possibility is that the observed sealevel variations could be related to changes in the strength of the Beaufort Gyre. Two recent studies [Proshutinsky et al., 2009; Giles et al., 2012] have shown that changes in WSC over the Amerasian basin after about 2003 led to a significant spin up of the Beaufort Gyre and an increase in the freshwater content in the gyre. They have found a significant anti-correlation between WSC and both sea level and freshwater content in the Beaufort Gyre. Giles et al. [2012] have also suggested that the recent decline in sea ice extent over the Arctic might have enhanced the efficiency of the wind to spin up and spin down the Beaufort Gyre. During a spin up of the gyre, water piles up in the gyre interior, which results in sea level rising in the gyre interior and falling on the margins of the gyre (i.e., on the coast). The opposite occurs during a spin down of the gyre. Hence, the strengthening of the Beafort gyre after 2003 is consistent with the sea-level decline observed in the East Siberian Sea during the same period. In order to investigate this possibility, we have first looked at the WSC averaged over the region of maximum decrease in WSC in the Beaufort Gyre $\left(78^{\circ}-79^{\circ} \mathrm{N}, 155^{\circ}-159^{\circ} \mathrm{W}\right)$ [see Figure 1 of Giles et al., 2012] during the period 2000-2009 and compared it to a sea ice index [Fetterer et al., 2002] of the Arctic (Figure 11a). There are a number of features that are worth commenting. First, there is a substantial decrease in WSC (increase in anti-cyclonicity) of more than four standard deviations below the mean after 2003, which is unique over the whole period. Second, this decrease in WSC coincides with a rapid decline in sea ice extent over the Arctic.

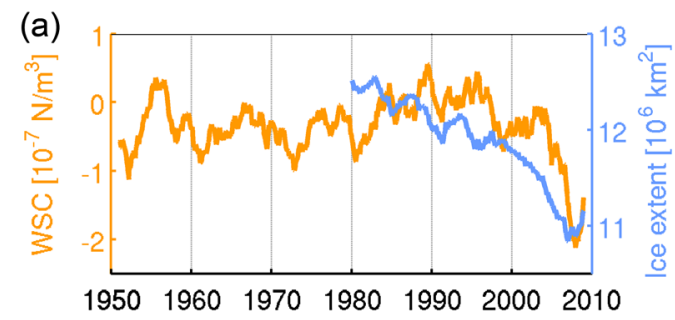

(b)

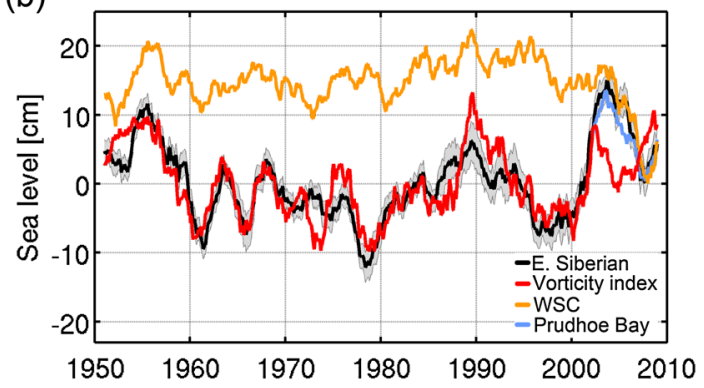

Figure 11. A comparison of the WSC averaged over the region of maximum WSC decrease in the Beaufort Gyre $\left(78-79^{\circ} \mathrm{N}, 155-159^{\circ} \mathrm{W}\right)$ during the period 2000-2009 (orange line) with (a) a sea ice index [Fetterer et al., 2002] of the Arctic Ocean (blue line) and (b) the IB-corrected sea level in the East Siberian Sea (black line) and from the tide gauge record in Prudhoe Bay (blue line). The vorticity index is also shown (red line). The WSC in Figure 11b has been adjusted so that for the period 2002-2010, it has the same standard deviation as the sea level.
[51] It is worth noting that if a relationship between sea level and changes in the Beaufort Gyre exists, the decline in sea level after 2003 should also be observed in other tide gauge records in the Amerasian basin. Hence, in order to confirm this relationship, we have compared the WSC with both the sea level from the tide gauge record at Prudhoe Bay (in Alaska, see Figure 1b) and the sea level in the East Siberian Sea (Figure 11b). We note that the substantial increase in anti-cyclonicity after 2003 coincides in phase with the sea-level decline in both the Prudhoe Bay and the East Siberian Sea. Moreover, the magnitude of the decline is very similar in both regions, as one would expect from a change in the large-scale ocean circulation over the Amerasian basin. This result suggests that the decline in coastal sea level in the Western Arctic Ocean could be part of a large-scale signal related to changes in the strength of the Beaufort Gyre driven by changes in WSC and ice extent.

\section{Summary and Conclusions}

[52] In this paper, we have examined inter-annual to decadal sea-level variations from tide gauge records along the Norwegian coast and in the Arctic Ocean, paying particular attention to their relationship with large-scale atmospheric forcing. We have found that the IB effect explains a significant percent of the low pass-filtered (2 year running mean) sea-level variance on the Norwegian coast $(36 \%)$ and in the Barents $(38 \%)$, Kara (34\%), and Laptev $(24 \%)$ Seas, while its contribution is almost negligible in the East Siberian and Chukchi Seas. These results are in good agreement with previous findings [Proshutinsky et al., 2004, 2007; Richter et al., 2012a]. The relationship between sea-level and large-scale atmospheric forcing has also been explored by comparing the regional sea-level variability with the AO index. The correlation between sea level and the AO index is significant in all regions except in the East Siberian and Chukchi Seas, even after correcting for the IB effect (Table 2), suggesting that the relationship is not only due to the effect of the atmospheric pressure. The relationship with the AO index is temporally variable, being stronger for the period 1950-1995 and almost vanishing after 1995 in all regions. The lack of correlation after 1995 was already reported in previous studies [Poshutinsky et al., 2007; Henry et al., 2012]. In the Laptev, East Siberian, and Chukchi Seas, the AO index fails to reproduce many of the major features observed during the whole period 1950-2009, not only after 1995.

[53] A comparison of the low pass-filtered sea-level variability in the six regions together with the results of a cross-correlation analysis between regions have shown that, while correlations are significant for all pairs of regions, there are also significant differences. In particular, we have identified two large regions of highly coherent sea-level variability: a first one that includes the Norwegian coast and the Barents and Kara Seas, and a second one that covers the region from the Laptev Sea to the Chukchi Sea, where sea-level variations are relatively larger than in the first region. A remarkable feature is the substantial sea-level increase $(\sim 22 \mathrm{~cm})$ in the East Siberian Sea between 2000 and 2003 and the subsequent decline $(\sim 15 \mathrm{~cm})$ between 2004 and 2008. This feature is unique to the East Siberian Sea and is not reflected in the AO index. 
[54] The variability along the Norwegian coast and also in the Barents and Kara Seas is largely due to changes in the longshore wind and to the associated Ekman transport and downwelling, but there is also a significant fraction related to a signal propagating along the eastern boundary of the North Atlantic. This has been demonstrated by reconstructing sea level along the Norwegian coast by combining the effect of the longshore wind with the contribution of this coherent sea-level signal originating on the eastern boundary of the North Atlantic as observed in the tide gauge record at Newlyn (in the Eastern North Atlantic). The correlation between the reconstructed and the observed sea level is 0.84 on the Norwegian coast, which is considerably higher than if only the longshore wind contribution was considered (0.62). The correlation between the sea level and the reconstructed signal is also very high in the Barents (0.76) and Kara Seas (0.72), suggesting that this signal may propagate further north into those regions. We have also investigated the contribution of the steric and mass components of sea level along the Norwegian coast. Our results show that the steric component explains $\sim 61 \%$ of the IB-corrected sea-level variability.

[55] In the Laptev, East Siberian, and Chukchi Seas, we have shown that sea-level variability is very sensitive to shifts between cyclonic or anti-cyclonic atmospheric circulation. The variability in the cyclonic circulation has been characterized by means of an atmospheric vorticity index, which has been shown to reproduce the major features of the observed sea-level variability over the period 1950-1999, with correlations ranging from 0.73 in the Chukchi Sea to 0.81 in the East Siberian Sea. The relationship between sea level and the vorticity index is established, to a large extent, through the response of the ocean to changes in the longshore wind. We have found that the vorticity index reproduces most of the sea-level increase observed in the East Siberian Sea from 2000 to 2002 . However, the good agreement between sea level in the East Siberian Sea and both the vorticity index and the longshore wind disappears after 2002. Particularly interesting is the significant sea-level decline $(\sim 15 \mathrm{~cm})$ observed in the East Siberian Sea from 2004 to 2008 despite the fact that both the vorticity index and the longshore wind show a positive trend. We have provided evidence using WSC data over the Western Arctic Ocean and sea level from a tide gauge in the Prudhoe Bay (in Alaska) that such decline in sea level could be related to the strengthening of the Beaufort Gyre in recent years [Proshutinsky et al., 2009; Giles et al., 2012].

[56] Finally, it is useful to highlight the main results of this study.

[57] 1. We have identified two large areas of high coherence: (a) the Norwegian, Barents, and Kara Seas and (b) the Laptev, East Siberian, and Chukchi Seas.

[58] 2. We have provided evidence of a new contribution to sea-level variability in the Norwegian Sea resulting from the poleward propagation of sea-level fluctuations along the eastern boundary of the North Atlantic. Results suggest that this signal could also affect the Barents and Kara Seas.

[59] 3. Steric sea-level changes explain a significant part of the sea-level variability in the coastal zone of the Norwegian Sea. When quantifying the steric component, it is critical to use $T / S$ observations taken on the eastern side of the NwAC.
[60] 4. We have introduced a vorticity index that explains most of the major features of the sea-level variability in the Laptev, East Siberian, and Chukchi Seas. The relationship between the vorticity index and sea level is largely due to the response of the ocean to the longshore wind.

[61] 5. We have identified a sea-level increase of $\sim 22 \mathrm{~cm}$ between 2000 and 2003 and a decline of $\sim 15 \mathrm{~cm}$ between 2004 and 2008 in the East Siberian Sea. Both features are unique to the East Siberian Sea. Sea level increased by only $\sim 5 \mathrm{~cm}$ between 2000 and 2005 in the Kara Sea and by $\sim 12 \mathrm{~cm}$ between 2002 and 2004 in the Laptev Sea.

[62] 6. The sea-level increase between 2000 and 2003 in the East Siberian Sea is mostly explained by the vorticity index. However, the subsequent decline from 2004 to 2008 is not reflected in the vorticity index. We have shown that such decline could be related to the strengthening of the Beaufort Gyre observed in recent years.

[63] As a final remark, several studies have attempted to infer the variability of the NwAC using sea-level observations from tide gauge records along the Norwegian coast [Skagseth et al., 2004; Richter et al., 2012b]. Because the transport of the NwAC, especially at the Svinøy section, is largely driven by local wind forcing [Skagseth et al., 2004; Richter et al., 2012b], and we have provided evidence that sea-level variability along the Norwegian coast has a contribution of Atlantic origin in addition to that from the wind, we propose that taking into account the Atlantic signal (by subtracting it from the tide gauge records) may provide a better estimate of the NwAC.

[64] Acknowledgments. F. M. Calafat was supported under a Marie Curie International Outgoing Fellowship within the 7th European Community Framework Programme (grant PIOF-GA-2010-275851). D. P. Chambers was supported under a grant from the NASA Interdisciplinary Science Sponsored Research program. The hydrographic station at Skrova was obtained from the Institute of Marine Research, Bergen, Norway. This research would not have been possible without the tide gauge records from the Permanent Service for Mean Sea Level, housed at the National Oceanography Centre, Liverpool, UK. The authors wish to thank two anonymous reviewers for their comments on an earlier draft of this paper which helped improve it.

\section{References}

Barnett, T. P., and R. Preisendorfer (1987), Origins and levels of monthly and seasonal forecast skill for United States surface air temperatures determined by canonical correlation analysis. Mon. Wea. Rev., 115, 1825-1850.

Benada, J. R. (1997), PO.DAAC merged GDR (TOPEX/Poseidon) generation B user's handbook. Version 2.0. JPL PO.DAAC 068.D002, 124 pp.

Bindoff, N., et al. (2007), Observations: oceanic climate change and sea level, in Climate Change 2007: The Physical Science Basis. Contribution of Working Group I to the Fourth Assessment Report of the Intergovernmental Panel on Climate Change, edited by S. Solomon, D. Qin, M. Manning, Z. Chen, M. Marquis, K. B. Averyt, M. Tignor, and H. L. Miller, pp. 385-432, Cambridge University Press, Cambridge.

Bingham, R. J., and C. W. Hughes (2012), Local diagnostics to estimate density-induced sea level variations over topography and along coastlines, J. Geophys. Res., 117, C01013, doi:10.1029/2011JC007276.

Bromirski, P. D., A. J. Miller, R. E. Flick, and G. Auad (2011), Dynamical suppression of sea level rise along the Pacific coast of North America: Indications for imminent acceleration, J. Geophys. Res., 116, C07005, doi:10.1029/2010JC006759.

Calafat, F. M., D. Chambers, and M. N. Tsimplis (2012a), Mechanisms of decadal sea level variability in the Eastern North Atlantic and the Mediterranean Sea, J. Geophys. Res., 117, C09022, doi:10.1029/2012JC008285.

Calafat, F. M., G. Jordà, M. Marcos, and D. Gomis (2012b), Comparison of

Mediterranean sea level variability as given by three baroclinic models, J. Geophys. Res., 117, C02009, doi:10.1029/2011JC007277.

Cazenave, A., and W. Llovel (2010), Contemporary sea level rise, Annual Review of Marine Science, 2, 145-173. 


\section{CALAFAT ET AL.: DECADAL SEA-LEVEL VARIABILITY}

Chelton, D., and R. Davis (1982), Monthly mean sea level along the west coast of North America, J. Phys. Oceanogr., 12, 757-784.

Church, J. A., and N. J. White (2011), Sea-level rise from the late 19th to the early 21st century, Surv. Geophys., 32, 585-602, doi:10.1007/ s10712-011-9119-1.

Clarke, A. J., and A. Lebedev (1999), Remotely driven decadal and longer changes in the coastal Pacific waters of the Americas, J. Phys. Oceanogr., $29,828-835$.

Dmitrenko, I., S. Kirillov, H. Eicken, and N. Markova (2005), Wind-driven summer surface hydrography of the eastern Siberian shelf, Geophys. Res. Lett., 32, L14613, doi:10.1029/2005GL023022.

Dmitrenko, I. A., S. A. Kirillov, and L. B. Tremblay (2008), The long-term and interannual variability of summer fresh water storage over the eastern Siberian shelf: Implication for climatic change, J. Geophys. Res., 113, C03007, doi:10.1029/2007JC004304.

Dmitrenko, I. A., S. A. Kirillov, L. B. Tremblay, H. Kassens, O. A. Anisimov, S. A. Lavrov, S. O. Razumov, and M. N. Grigoriev (2011), Recent changes in shelf hydrography in the Siberian Arctic: Potential for subsea permafrost instability, J. Geophys. Res., 116, C10027, doi:10.1029/2011JC007218.

Emery, W. J., and R. E. Thomson (1998), Data Analysis Methods in Physical Oceanography, 634 pp., Pergamon Press, Oxford.

Enfield, D. B., and J. S. Allen (1980), On the structure and dynamics of monthly mean SLAs along the Pacific coast of North and South America, J. Phys. Oceanogr., 10, 557-578.

Fetterer, F., K. Knowles, W. Meier, and M. Savoie (2002), Sea Ice Index, Boulder, CO, National Snow and Ice Data Center.

Forman, S. L., and G. L. Johnson (1998), Prospectus for the Russian-American Initiative on Shelf-Land Environments in the Arctic (RAISE), Arctic Research Consortium of the United States (ARCUS), Fairbanks, Alaska, 50 pp.

Giles, K. A., S. W. Laxon, A. L. Ridout, D. J. Wingham, and S. Bacon (2012), Western Arctic Ocean freshwater storage increased by winddriven spin-up of the Beaufort Gyre, Nat. Geosci., 5 (3), 194-197.

Gill, A. E., and P. P. Niiler (1973), The theory of the seasonal variability of the ocean, Deep Sea Res., 20, 141-177.

Gill, A. E. (1982), Atmosphere-Ocean Dynamics, 662 pp, Academic Press, San Diego, Calif.

Henry, O., P. Prandi, W. Llovel, A. Cazenave, S. Jevrejeva, D. Stammer, B. Meyssignac, and N. Koldunov (2012), Tide gauge-based sea level variations since 1950 along the Norwegian and Russian coasts of the Arctic Ocean: Contribution of the steric and mass components, $J$. Geophys. Res., 117, C06023, doi:10.1029/2011JC007706.

Hughes, C. W., and P. M. Meredith (2006), Coherent sea-level fluctuations along the global continental slope, Philos. Trans. R. Soc., 364, 885-901, doi:10.1098/rsta.2006.1744

Ingleby B., and Huddleston M. (2007), Quality control of ocean temperature and salinity profiles - historical and real-time data, J. Marine Systems, 65 , 158-17, doi:10.1016/j.jmarsys.2005.11019.

Johnson, M. A., and I. Polyakov (2001), The Laptev Sea as a source for recent Arctic Ocean salinity change, Geophys. Res. Lett., 28(10), 2017-2020.

Kalnay, E., et al. (1996), The NCEP/NCAR 40-Year Reanalysis Project, Bull. Am. Meteorol. Soc., 77 (3), 437-471.

Llovel, W., B. Meyssignac, and A. Cazenave (2011), Steric sea level variations over 2004-2010 as a function of region and depth: Inference on the mass component variability in the North Atlantic Ocean, Geophys. Res. Lett., 38, L15608, doi:10.1029/2011GL047411.

Marcos, M. and M. N. Tsimplis (2007), Forcing of coastal sea level rise patterns in the North Atlantic and the Mediterranean Sea, Geophys. Res. Lett., 34, L18604, doi:10.1029/2007GL030641.

Marcos, M., M. N. Tsimplis, and F. M. Calafat (2012), Inter-annual and decadal sea level variations in the north-western Pacific marginal seas, Prog. Oceanogr., 105, 4-21.

Meehl, G. A., T. F. Stocker, and W. D. Collins (2007), Global climate projections. In: Climate Change 2007: The Physical Science Basis. Contribution of Working Group I to the Fourth Assessment Report of the Intergovernmental Panel on Climate Change, Solomon, S., Qin, D., Manning, M., et al. (Eds.), pp. 749-844, Cambridge University Press, Cambridge and New York.

Merrifield, M. A. (2011), A shift in western tropical Pacific sea-level trends during the 1990s, J. Climate, 24, 4126-4138, doi:10.1175/2011JCLI3932.1.
Meyssignac, B., F. M. Calafat, S. Somot, V. Rupolo, P. Stocchi, W. Llovel, and A. Cazenave (2011), Two-dimensional reconstruction of the Mediterranean sea level over 1970-2006 from tide gage data and regional ocean circulation model outputs, Global Planet. Change, 77, 49-61.

Miller, L., and B. C. Douglas (2007), Gyre-scale atmospheric pressure variations and their relation to 19th and 20th century sea level rise, Geophys. Res. Lett., 34, L16602, doi:10.1029/2007GL030862.

Morison, J., J. Wahr, R. Kwok, and C. Peralta-Ferriz (2007), Recent trends in Arctic Ocean mass redistribution revealed by GRACE, Geophys. Res. Lett., 34, L07602, doi:10.1029/2006GL029016.

Orvik, K. A., and Ø. Skagseth (2005), Heat flux variations in the eastern Norwegian Atlantic Current toward the Arctic from moored instruments, 1995-2005, Geophys. Res. Lett., 32, L14610, doi:10.1029/2005GL023487.

Pavlov, V. K. (2001), Seasonal and long-term sea level variability in the marginal seas of the Arctic Ocean, Polar Res., 20(2), 153-160.

Ponte, R. M. (1999), A preliminary model study of the large-scale seasonal cycle in bottom pressure over the global ocean, J. Geophys. Res., 104 (C1), 1289-1300, doi:10.1029/1998JC900028.

Ponte, R. M. (2006), Low-frequency sea level variability and the inverted barometer effect, J. Atmos. Oceanic Technol., 23, 619-629. doi: http:// dx.doi.org/10.1175/JTECH1864.1.

Proshutinsky, A., V. Pavlov, and R. H. Bourke (2001), Sea level rise in the Arctic Ocean, Geophys. Res. Lett., 28, 2237-2240.

Proshutinsky, A., I. M. Ashik, E. N. Dvorkin, S. Häkkinen, R. A. Krishfield, and W. R. Peltier (2004), Secular sea level change in the Russian sector of the Arctic Ocean, J. Geophys. Res., 109, C03042, doi:10.1029/2003JC002007.

Proshutinsky, A., I. Ashik, S. Häkkinen, E. Hunke, R. Krishfield, M. Maltrud, W. Maslowski, and J. Zhang (2007), Sea level variability in the Arctic Ocean from AOMIP models, J. Geophys. Res., 112, C04S08, doi:10.1029/ 2006JC003916.

Proshutinsky, A., R. Krishfield, M.-L. Timmermans, J. Toole, E. Carmack, F. McLaughlin, W. J. Williams, S. Zimmermann, M. Itoh, and K. Shimada (2009), Beaufort Gyre freshwater reservoir: State and variability from observations, J. Geophys. Res., 114, C00A10, doi:10.1029/ 2008JC005104.

Proshutinsky, A., et al. (2011) The Arctic (Ocean), Bull. Am. Meteorol. Soc., 92(6), S145-S148.

Rahmstorf, S. (2006), Thermohaline ocean circulation, in Encyclopedia of Quaternary Sciences, edited by S. A. Elias. Elsevier, Amsterdam.

Richter, K., J. E. Ø. Nilsen, and H. Drange (2012a), Contributions to sea level variability along the Norwegian coast for 1960-2010, J. Geophys. Res., 117, C05038, doi:10.1029/2011JC007826.

Richter, K., O. H. Segtnan, and T. Furevik (2012b), Variability of the Atlantic inflow to the Nordic Seas and its causes inferred from observations of sea surface height, J. Geophys. Res., 117, C04004, doi:10.1029/ 2011JC007719.

Skagseth, Ø., K. A. Orvik, and T. Furevik (2004), Coherent variability of the Norwegian Atlantic Slope Current derived from TOPEX/ERS altimeter data, Geophys. Res. Lett., 31, L14304, doi:10.1029/2004GL020057.

Sturges, W., and B. C. Douglas (2011), Wind effects on estimates of sea level rise, J. Geophys. Res., 116, C06008, doi:10.1029/ 2010JC006492.

Tsimplis, M. N., M. Marcos, S. Somot, and B. Barnier (2008), Sea level forcing in the Mediterranean Sea between 1960 and 2000, Global Planet. Change, 63, 325-332, doi:10.1016/j.gloplacha.2008.07.004.

Vermeer, M., and S. Rahmstorf (2009), Global sea level linked to global temperature, Proc. Natl. Acad. Sci. U.S.A. 106, 21527.

Volkov, D. L., and M.-I. Pujol (2012), Quality assessment of a satellite altimetry data product in the Nordic, Barents, and Kara seas, J. Geophys. Res., 117, C03025, doi:10.1029/2011JC007557.

Volkov, D. L., G. Larnicol, and J. Dorandeu (2007), Improving the quality of satellite altimetry data over continental shelves, J. Geophys. Res. 112, C06020.

Woodworth, P. L., and R. Player (2003), The permanent service for mean sea level: An update to the 21 st century, J. Coastal Res., 19, 287-295.

Woodworth, P. L., N. Pouvreau, and G. Wöppelmann (2010), The gyrescale circulation of the North Atlantic and sea level at Brest, Ocean Sci., 6, 185-190. 